\title{
A Binary Logistic Regression Model for Severe Convective Weather with Numerical Model Data
}

\author{
Guqian Pang $\mathbb{D}^{1}{ }^{1}$ Jian He $\mathbb{D}^{1},{ }^{1}$ Yuming Huang, ${ }^{2}$ and Liuhong Zhang ${ }^{1}$ \\ ${ }^{1}$ Climate Center of Guangdong Province, Guangzhou 510080, China \\ ${ }^{2}$ Guangdong Meteorological Public Service Center, Guangzhou, China \\ Correspondence should be addressed to Jian He; jhe@gd121.cn
}

Received 20 March 2019; Revised 9 July 2019; Accepted 30 August 2019; Published 14 November 2019

Academic Editor: Enrico Ferrero

Copyright (c) 2019 Guqian Pang et al. This is an open access article distributed under the Creative Commons Attribution License, which permits unrestricted use, distribution, and reproduction in any medium, provided the original work is properly cited.

Based on meteorological observations and products of a GRAPES and an ECMWF model from March to April 2014, some indexes and parameters with good relevancy were selected as predictors. Through analyzing the spatial distributions and the binary logistic regressions of the indexes, estimated values of the predictors and severe convective weather diagnostic prediction equations were established to get a severe weather predictor $P$ for forecasting severe convective weather for the next 12 hours in Guangdong province. The equations were tested and analyzed, respectively, with the two models as well as the radiosonde data. The results indicated that the severe weather forecasts' CSI by the predictor $P$ was obviously higher than by any single index. The TT error between the models and the soundings was small, while the $K$ index of the models was more discrete than the soundings. The index MDPIs were 1 greater than the soundings, but their trends of change were consistent with the soundings.

\section{Introduction}

Severe convective weather is the main severe weather in the Guangdong Province, China, during its first flood season. The severe convective weather affecting Guangdong Province mainly includes severe thunderstorm wind gusts (gusts $\geq 17.2 \mathrm{~m} / \mathrm{s}$ ), hail, tornadoes, and short-time heavy rains (hourly rainfall $\geq 20 \mathrm{~mm}$ ). In recent years, there have been many researches on severe convective weather forecasting methods in the world. The comprehensive use of a physical quantity index for potential forecasting is one of the important methods. Li and Jianwen [1] pointed out that the downdraft convective available potential energy and wind index present the downward convection and micro-downburst, respectively. Downward convection is closely related with the altitude of the dry intrusive, the dryness of the air, the instability, and the humidity of the low-level atmosphere. A proper vertical wind shear is favorable to severe storms. The storm relative helicity is a predictive factor for severe storms. The bulk Richardson number reflects the balance between convective energy and dynamic effect. The energetic helicity index reflects the combination of the buoyancy energy and the dynamic effect.
The binary logistic regression model [2], based on the logistic function, is generally used to study the nature of dependence of a dichotomous response variable $(Y)$ on a number of explanatory variables $(X 1, X 2$, and $X k)$, which are either discrete or continuous in nature. Although used extensively in epidemiology, the use of logistic regression in the context of meteorology is of a recent origin. Sanchez et al. [3] have applied this model to the short-term forecast of hail risk in the province of Leon in the northwestern Iberian Peninsula of Spain.

A total of 31 indexes [4] describing conditions of humidity, stability, helicity, or precipitable water were used as input to a binary logistic regression model. Of the 31 indexes, 5 were selected: Showalter index (SI), wind speed at $500 \mathrm{hPa}$ (SPD500), dew point temperature at $850 \mathrm{hPa}$ (Td850), relative helicity between 0 and $3 \mathrm{~km}$ (SREH3 $\mathrm{km}$ ), and wet bulb zero height (WBZ). It is suggested that these results provide a new tool that complements those previously developed for this study area, toward improving severe storms prediction and pinpointing these storms in space and in time. Trenton and Labosier [5] examined drought persistence in the Southeastern United States by identifying spatial patterns of seasonal drought frequency and persistence, using logistic 
regression to calculate the odds and probability of drought persisting from one season to the next, and examined the effects of El Nino-Southern Oscillation (ENSO) drought persistence in the southeast. Lee [6] associated geopotential height and temperature fields to historic F2 and stronger United States' tornadoes days using binary logistic regression. Using output data from two Global Climate Models (GCMs), spanning five different model emissions scenarios, this synoptic climatology of tornadoes is then utilized in order to project the changes in the frequency and seasonality of tornadic environments due to a changing climate. Dasgupta and De [7] considered binary logistic regression models for prediction of convective developments from a prior knowledge of the values of the certain dynamic and thermodynamic parameters. Holden and Wright [8] pointed out that tornado distribution was shown to be significantly affected by topography and the density of potential observers. The binary logistic regression was used to predict actual tornado occurrences across England, Wales, and Scotland during the 5-year study period. Pablo et al. [9] introduced 31 stability indexes in a binary logistic regression model, which selected the most accurate ones for detecting hail days in the region, namely, the Showalter index, dew point temperature at $850 \mathrm{hPa}$, and TQ index. The new forecast tool shows satisfactory results and complements other studies in the same region, and it can be a useful tool for operational forecasters in predicting hail days and determining the spatial distribution of hailfalls.

In recent years, Pang et al. [10-13] used indexes calculated with the radiosonde data as a potential forecasting factor and made related studies on the severe convective weather potential forecasting in the Guangdong Province. Most of the researches were based on the real-time data, which are of poor temporal and spatial resolutions. To improve these resolutions, products of GRAPES, a new numerical weather prediction model (NWP) developed in China with a resolution of $12 \mathrm{~km}$, are adopted in this study. At the same time, ECMWF (EC) products with a resolution of $25 \mathrm{~km}$ were used to compare and analyze the prediction effects.

\section{Source of Data and Procedures of Calculating}

In this study, meteorological observation products of the GRAPES and EC models from March to April, 2014, were used. The severe convective weather includes severe thunderstorm wind gusts and short-term heavy rains. The indexes were calculated by the model data such as $K$ index TT index, MDPI index, and IQ index. Except for the original data of the models, no other products were used.

The calculation process consisted of the following four steps:

(1) Find out the severe convective weather events in Guangdong Province over the years.

(2) The criterion for judging whether a severe convective weather event occurred at a model grid is as follows: if there are three or more severe weather reports in a square from the center of a model grid to the adjacent grid; the grid recorded that there is severe convective weather, otherwise none.

(3) According to the spatial and temporal distribution characteristics of these model grid data, find out the indexes which have good correlation with the severe convective weather events.

(4) The binary logistic regression model will be established based on the indexes which determines whether severe convective weather events occurred and not. According to the binary logistic regression model, the prediction factor $(P)$ of severe convective weather events will be calculated.

\section{Correlations between Indexes and Severe Convective Weather Events}

Based on 184904 grid samples of GRAPES from March to April, 2014, and the correlation coefficients of 16 indexes (Table 1) and severe convective weather were analyzed statistically. It was shown that the correlation coefficients of $K$ index, TT index, MDPI index, and IQ index with severe convective weather were among the highest and passed the significant test at 0.01 level, respectively, reaching $0.09,0.12$,

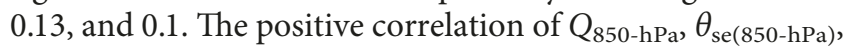
$T_{850-\mathrm{hPa}-500-\mathrm{hPa}}, \mathrm{WS}_{850-\mathrm{hPa}}, \mathrm{VV}_{850-\mathrm{hPa}}, \omega_{925-\mathrm{hPa}}, \mathrm{DIV}_{925-\mathrm{hPa}}$, $Q_{925-\mathrm{hPa}}, \theta_{\text {se }(925-\mathrm{hPa})}, \mathrm{VV}_{925-\mathrm{hPa}}$, and other indexes with severe convective weather were weak but passed the significant test at 0.01 level. The negative correlation of $\mathrm{VFD}_{850-\mathrm{hPa}}$ and $\mathrm{VFD}_{925-\mathrm{hPa}}$ was weak and passed the significant test at 0.01 level (Table 2). Considering comprehensively, the indexes which had higher correlations with severe convective weather events, the $K$ index, TT index, MDPI index, and IQ index were selected.

\section{Establishment of Binary Logistic Regression Model}

4.1. Probability Formula of Logistic Regression. Regression is a statistical analysis method [11] that studies whether there is a linear or nonlinear relationship between one or more independent variables and a dependent variable. It is suitable to analyze the relationship between the occurrence of severe convective weather (dependent variable) and each index (independent variable) by binary logistic regression.

The result of a test sample under the action of a set of independent variables is represented by the indicator variable $Y$. The assignment rules are as follows:

$Y= \begin{cases}1, & \text { the result of severe convective weather occurred, } \\ 0, & \text { the result of no severe convective weather occurred, }\end{cases}$

where $P$ is the probability of severe convective weather occurred, while $Q$ is the probability of no severe convective weather occurred. The computational method of $P$, which used the logistic regression formula, is

$$
P=\frac{e^{\beta_{0}+\beta_{1} x_{1}+\beta_{2} x_{2}+\cdots++\beta_{m} x_{m}}}{1+e^{\beta_{0}+\beta_{1} x_{1}+\beta_{2} x_{2}+\cdots++\beta_{m} x_{m}}} .
$$


TABLE 1: Calculated indexes.

\begin{tabular}{lc}
\hline Index & $\begin{array}{c}\text { Abbreviation of } \\
\text { index }\end{array}$ \\
\hline $850 \mathrm{hPa}$ vapor flux divergence & $\mathrm{VFD}_{850-\mathrm{hPa}}$ \\
$K \mathrm{Index}$ & $\mathrm{K}$ \\
$850 \mathrm{hPa}$ specific humidity & $Q_{850-\mathrm{hPa}}$ \\
Total totals & $\mathrm{TT}$ \\
The microburst-day potential index & $\mathrm{MDPI}$ \\
$850 \mathrm{hPa}$ potential pseudoequivalent & $\theta_{\text {se }(850-\mathrm{hPa})}$ \\
temperature & \\
Temperature difference between $850 \mathrm{hPa}$ and & $T_{850-\mathrm{hPa}-500-\mathrm{hPa}}$ \\
$500 \mathrm{hPa}$ & $\mathrm{WS}_{850-\mathrm{hPa}}$ \\
$850 \mathrm{hPa}$ wind shear & $\mathrm{VV}_{850-\mathrm{hPa}}$ \\
$850 \mathrm{hPa}$ vertical velocity & $\omega_{925-\mathrm{hPa}}$ \\
$925 \mathrm{hPa}$ vorticity & $\mathrm{DIV}_{925-\mathrm{hPa}}$ \\
$925 \mathrm{hPa}$ divergence & $\mathrm{VFD}_{925-\mathrm{hPa}}$ \\
$925 \mathrm{hPa}$ vapor flux divergence & $Q_{925-\mathrm{hPa}}$ \\
$925 \mathrm{hPa}$ specific humidity & $\theta_{\text {se }(925-\mathrm{hPa})}$ \\
$925 \mathrm{hPa}$ Potential pseudoequivalent & $\mathrm{VV}_{925-\mathrm{hPa}}$ \\
temperature & IQ \\
$925 \mathrm{hPa}$ vertical velocity & \\
Integral Q
\end{tabular}

where $\beta_{0}$ is the constant term unrelated to the factors $x_{i}$ and $\beta_{1}, \beta_{2}, \ldots, \beta_{m}$ are regression coefficients which are the contributions of factor $x_{i}$ to $P$.

With formula $P+Q=1$, we could get the formula to calculate the probability of no severe convective weather occurred:

$$
Q=\frac{1}{1+e^{\beta_{0}+\beta_{1} x_{1}+\beta_{2} x_{2}+\cdots++\beta_{m} x_{m}}} .
$$

It can be seen from the above two equations that the probability caused by a test sample has a curvilinear relationship to the related factors.

The ratio of the two probabilities is

$$
\frac{P}{Q}=e^{\beta_{0}+\beta_{1} x_{1}+\beta_{2} x_{2}+\cdots++\beta_{m} x_{m}}
$$

We call $P / Q$ the ratio and $\beta_{1}, \beta_{2}, \ldots, \beta_{m}$ the logistic regression coefficients.

4.2. Derivation of Logistic Regression Coefficients. Suppose we have $m$ factors such as $x_{1}, x_{2}, \ldots, x_{m}$, the value of $Y$ is 1 or 0 , and $n$ samples were taken:

$$
\begin{array}{lc}
\text { Factors } & \text { Values } \\
x_{1}, x_{2}, \ldots, x_{m} & Y \\
x_{11}, x_{12}, \ldots, x_{1 m} & Y_{1} . \\
x_{21}, x_{22}, \ldots, x_{2 m} & Y_{2} \\
\vdots & \vdots \\
x_{n 1}, x_{n 2}, \ldots, x_{n m} & Y_{n}
\end{array}
$$

Next, we derived the regression coefficients by the maximum likelihood estimation [3]:

$$
L=\prod_{i=1}^{n} P_{i}^{y_{i}} Q_{i}^{1-y_{i}} .
$$

In the above formula, $P_{i}=e^{\beta_{0}+\beta_{1} x_{i 1}+\beta_{2} x_{i 2}+\cdots++\beta_{m} x_{i m}} /(1+$ $\left.e^{\beta_{0}+\beta_{1} x_{i 1}+\beta_{2} x_{i 2}+\cdots++\beta_{m} x_{i m}}\right), Q_{i}=1 /\left(1+e^{\beta_{0}+\beta_{1} x_{i 1}+\beta_{2} x_{i 2}+\cdots+}+\beta_{m} x_{i m}\right)$, $i=1,2, \ldots, n$.

Take the natural logarithm of formula (6),

$$
\ln L=\sum_{t=1}^{n}\left[y_{i} \ln P_{i}+\left(1-y_{i}\right) \ln Q_{i}\right] \text {. }
$$

Solving the equations (8), the maximum likelihood estimators of $\beta_{0}, \beta_{1}, \beta_{2}, \ldots, \beta_{m}$ can be obtained:

$$
\left\{\begin{array}{l}
\frac{\partial \ln L}{\partial \beta_{0}}=0 \\
\vdots \\
\frac{\partial \ln L}{\partial \beta_{m}}=0 .
\end{array}\right.
$$

\section{Establishment of Severe Convective Weather Forecasting Equation Based on Two NWP Models}

By using SPSS software, GRAPES indexes of 184904 grids and severe convective weather reports from March to April, 2014, were analyzed on binary logistic regression. The outputs are given in Table 3 .

In Table 3, $B$ is the independent variable coefficient, S.E. is the standard error, which is the average error of the estimated value, Wals is a statistic, which is used to test whether the independent variable has an influence on the dependent variable, and Sig is the significance. The larger Wals is, the smaller Sig it corresponds to is and the more significant its influence is. Df is the degree of freedom. Exp $(B)$ is the odds ratio, also known as relative risk. It means that the multiple of severe convective weather probability increases for each additional unit of the independent variable when $\exp (B)$ is greater than 1 . Substituting the independent coefficient into the equation, the severe convective weather forecasting equation of the GRAPES model is obtained:

$$
\begin{aligned}
P_{\text {GRAPES }}= & \frac{e^{a 1}}{1+e^{a 1}}, \\
a 1= & -16.251+0.116 * K+0.002 * \mathrm{IQ} \\
& +0.603 * \mathrm{MDPI}-0.23 * \mathrm{TT},
\end{aligned}
$$

where $P_{\text {GRAPES }}$ is the forecast factor of the GRAPES model, whose value is between 0 and 1 .

Similarly, the binary logistic regression results for EC indexes of 35670 grids are given in Table 4 .

Substituting the independent coefficient into the equation, the severe convective weather forecasting equation of the EC model is obtained: 
TABle 2: Correlation coefficients between indexes and severe convective weather from March to April, 2014.

\begin{tabular}{lcccccccc}
\hline Index & $\mathrm{VFD}_{850-\mathrm{hPa}}$ & $K$ & $Q_{850-\mathrm{hPa}}$ & $\mathrm{TT}$ & $\mathrm{MDPI}$ & $\theta_{\text {se( } 850-\mathrm{hPa}}$ & $T_{850-\mathrm{hPa}-500-\mathrm{hPa}}$ & $\mathrm{WS}_{850-\mathrm{hPa}}$ \\
\hline Correlation coefficient & -0.02 & 0.09 & 0.06 & 0.12 & 0.13 & 0.05 & 0.08 & 0.04 \\
Index & $\mathrm{VV}_{850-\mathrm{hPa}}$ & $\omega_{925-\mathrm{hPa}}$ & $\mathrm{DIV}_{925-\mathrm{hPa}}$ & $\mathrm{VFD}_{925-\mathrm{hPa}}$ & $\mathrm{Q}_{925-\mathrm{hPa}}$ & $\theta_{\text {se }(925-\mathrm{hPa})}$ & $\mathrm{VV}$ \\
Correlation coefficient & 0.02 & 0.02 & -0.04 & -0.05 & 0.07 & 0.05 & 0.05 & 0.1 \\
\hline
\end{tabular}

TABLE 3: Indexes in the equation-based GRAPES model.

\begin{tabular}{lcccccc}
\hline Index & $B$ & SE & Wals & Df & Sig. & Exp $(B)$ \\
\hline K & 0.116 & 0.12 & 100.168 & 1 & 0.000 & 1.123 \\
IQ & 0.002 & 0.000 & 751.513 & 1 & 0.000 & 1.002 \\
MDPI & 0.603 & 0.048 & 155.081 & 1 & 0.000 & 1.828 \\
TT & -0.23 & 0.011 & 4.803 & 1 & 0.000 & 0.977 \\
Constant & -16.251 & 0.41 & 1570.145 & 1 & 0.000 & 0.000 \\
\hline
\end{tabular}

TABLE 4: Indexes in the equation-based EC model.

\begin{tabular}{lcccccc}
\hline Index & $B$ & S.E. & Wals & Df & Sig. & Exp $(B)$ \\
\hline$K$ & -0.098 & 0.006 & 243.151 & 1 & 0.000 & 0.906 \\
IQ & 0.511 & 24.752 & 0.000 & 1 & 0.984 & 1.667 \\
MDPI & 0.067 & 0.169 & 0.155 & 1 & 0.694 & 1.069 \\
TT & 0.20 & 0.013 & 244.178 & 1 & 0.000 & 1.222 \\
Constant & -9.834 & 0.356 & 761.342 & 1 & 0.000 & 0.000 \\
\hline
\end{tabular}

$$
\begin{aligned}
P_{\mathrm{EC}}= & \frac{e^{a 2}}{1+e^{a 2}}, \\
a 2= & -9.834-0.098 * K+0.511 * \mathrm{IQ} \\
& +0.067 * \mathrm{MDPI}+0.2 * \mathrm{TT},
\end{aligned}
$$

where $P_{\mathrm{EC}}$ is the forecast factor of EC model, whose value is between 0 and 1.

\section{Goodness-of-Fit Testing of Forecasting Equation}

The regression testing is required after constructing the logistic regression model. There are two methods for regression testing, which are regression coefficient testing and goodness-of-fit testing. We tested the goodness-of-fit of the regression equation. There are three kinds of tests for the goodness-of-fit, -2 logarithm likelihood values (the logistic regression model uses the maximum likelihood for parameter estimation, and the likelihood value is the probability of obtaining the observation under certain parameter estimation conditions; the larger the maximum likelihood value, the better the model fits), the Cox \& Snell R Square, and the Nagelkerke R Square (the better the effect, the closer the value is to 1 ). In Table 5, it could be seen that the Cox \& Snell R Square and the Nagelkerke R Square of the two models were not ideally fitted, and the results were 0.026 , $0.151,0.016$, and 0.088 . However, both the -2 logarithm likelihood values are large and obviously significant.

Table 6 is the verification of the GRAPE-based model. When the observation is equal to 0 , which means no severe convection weather occurred, the forecasting
TABLE 5: Goodness-of-fit testing of forecasting equation.

\begin{tabular}{lccc}
\hline NWP & -2 logarithm & Cox \& Snell R & Nagelkerke R \\
model & likelihood values & Square & Square \\
\hline GRAPES & $30591.374^{\mathrm{a}}$ & 0.026 & 0.151 \\
EC & $6648.102^{\mathrm{a}}$ & 0.016 & 0.088 \\
\hline
\end{tabular}

TABLE 6: The classification table of GRAPES-based model.

\begin{tabular}{lccc}
\hline \multirow{2}{*}{ Observation } & \multicolumn{2}{c}{ Forecasting } & Forecasting accuracy \\
& 0 & 1 & 89.4 \\
0 & 162033 & 19263 & 41.2 \\
1 & 2123 & 1485 & 88.4 \\
\hline
\end{tabular}

TABLE 7: The classification table of EC-based model.

\begin{tabular}{lccc}
\hline \multirow{2}{*}{ Observation } & \multicolumn{2}{c}{ Forecasting } & Forecasting accuracy \\
& 0 & 1 & 89.2 \\
0 & 31167 & 3758 & 36.2 \\
1 & 475 & 269 & 88.1 \\
\hline
\end{tabular}

succeeded 162,033 times and failed 19,263 times, reaching up to $89.4 \%$ accuracy. When the observation is equal to 1 , which means severe convection weather occurred, the forecasting succeeded 1,485 times and failed 2,123 times, reaching up to $41.2 \%$ accuracy. The total verification accuracy rate is $88.4 \%$, indicating that the GRAPES-based model was stable.

Table 7 is the verification of the EC-based model. When the observation is equal to 0 , which means no severe convection weather occurred, the forecasting succeeded 31,167 times and failed 3,758 times, reaching up to $89.2 \%$ accuracy. When the observation is equal to 1 , which means severe convection weather occurred, the forecasting succeeded 269 times and failed 475 times, reaching up to $36.2 \%$ accuracy. The total verification accuracy rate is $88.1 \%$, indicating that the EC-based model was also stable.

The total verification accuracy rate from Tables 6 and 7 is the number of successful forecasting times divided by the total number of forecasting times.

\section{Severe Convective Weather Forecast Evaluation of Forecast Equation}

There are three indicators for severe convective weather forecast evaluation, POD stands for probability of detection, FAR stands for false alarm ratio, and CSI stands for critical success index. The three indicators are calculated as follows: 
TABLE 8: The evaluation of the two equations.

\begin{tabular}{|c|c|c|c|c|c|c|c|}
\hline Model & Threshold of $P$ & $X$ & $Y$ & $Z$ & POD (\%) & FAR (\%) & CSI (\%) \\
\hline \multirow{8}{*}{ GRAPES } & 0.03 & 2260 & 1348 & 34966 & 62.64 & 93.93 & 5.86 \\
\hline & 0.04 & 1883 & 1725 & 25660 & 52.19 & 93.16 & 6.43 \\
\hline & 0.05 & 1485 & 2123 & 19263 & 41.16 & 92.84 & 6.49 \\
\hline & 0.06 & 1115 & 2493 & 14725 & 30.90 & 92.96 & 6.08 \\
\hline & 0.07 & 881 & 2727 & 11150 & 24.42 & 92.68 & 5.97 \\
\hline & 0.08 & 669 & 2939 & 8330 & 18.54 & 92.57 & 5.60 \\
\hline & 0.09 & 511 & 3097 & 5913 & 14.16 & 92.05 & 5.37 \\
\hline & 0.1 & 391 & 3217 & 4040 & 10.84 & 91.18 & 5.11 \\
\hline \multirow{9}{*}{$\mathrm{EC}$} & 0.02 & 539 & 205 & 12740 & 72.45 & 95.94 & 4.00 \\
\hline & 0.03 & 426 & 318 & 6635 & 57.26 & 93.97 & 5.77 \\
\hline & 0.04 & 269 & 475 & 3758 & 36.16 & 93.32 & 5.98 \\
\hline & 0.05 & 185 & 559 & 2389 & 24.87 & 92.81 & 5.90 \\
\hline & 0.06 & 269 & 475 & 3758 & 36.16 & 93.32 & 5.98 \\
\hline & 0.07 & 131 & 613 & 1581 & 17.61 & 92.35 & 5.63 \\
\hline & 0.08 & 51 & 693 & 779 & 6.85 & 93.86 & 3.35 \\
\hline & 0.09 & 29 & 715 & 545 & 3.90 & 94.95 & 2.25 \\
\hline & 0.1 & 14 & 730 & 370 & 1.88 & 96.35 & 1.26 \\
\hline
\end{tabular}

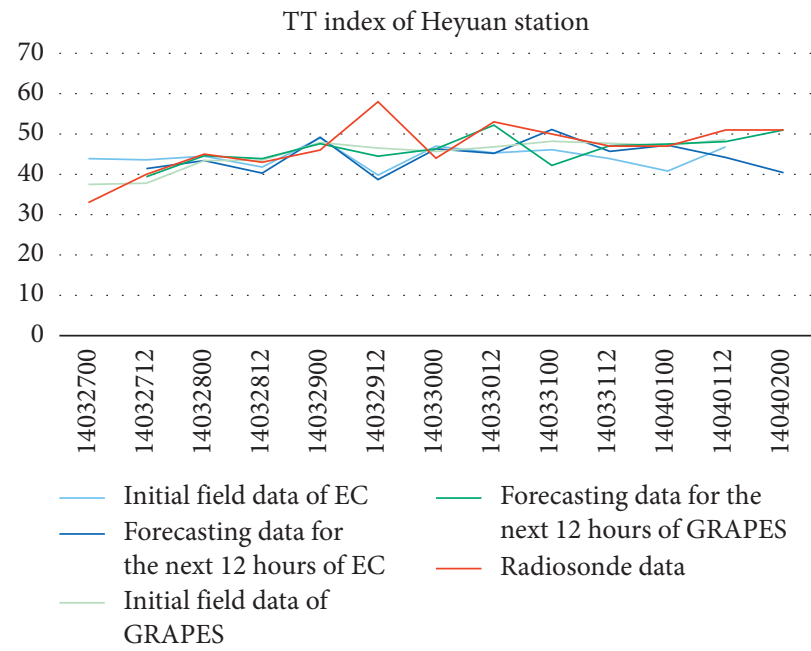

(a)

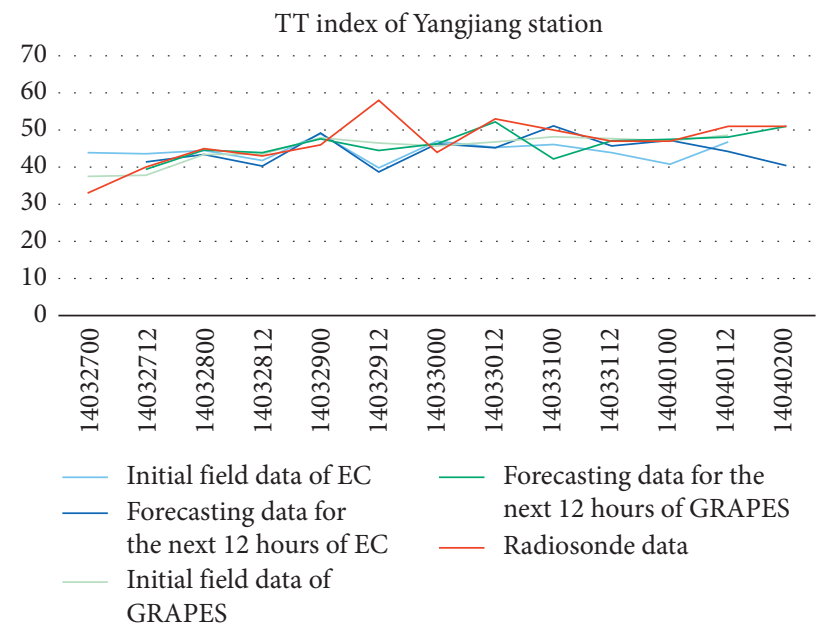

(c)

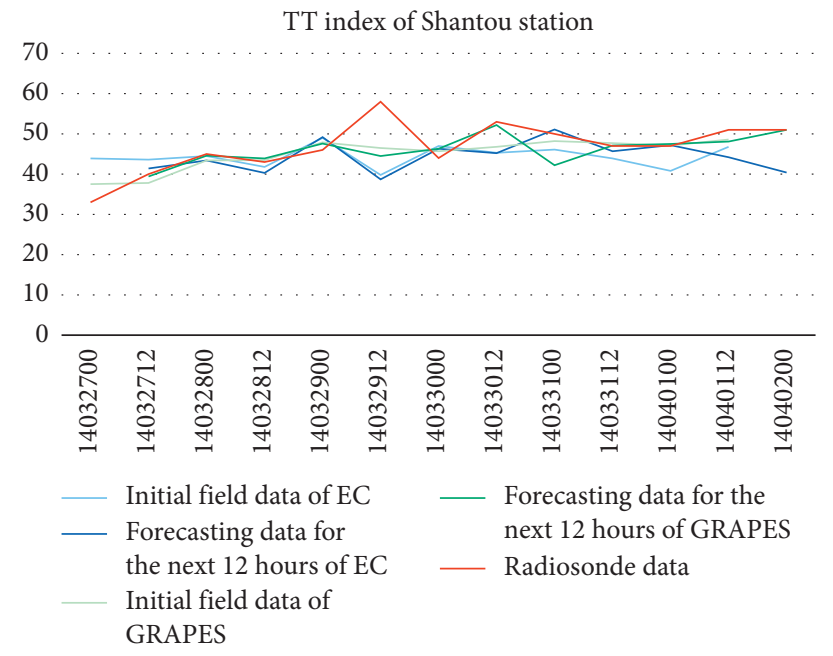

(b)

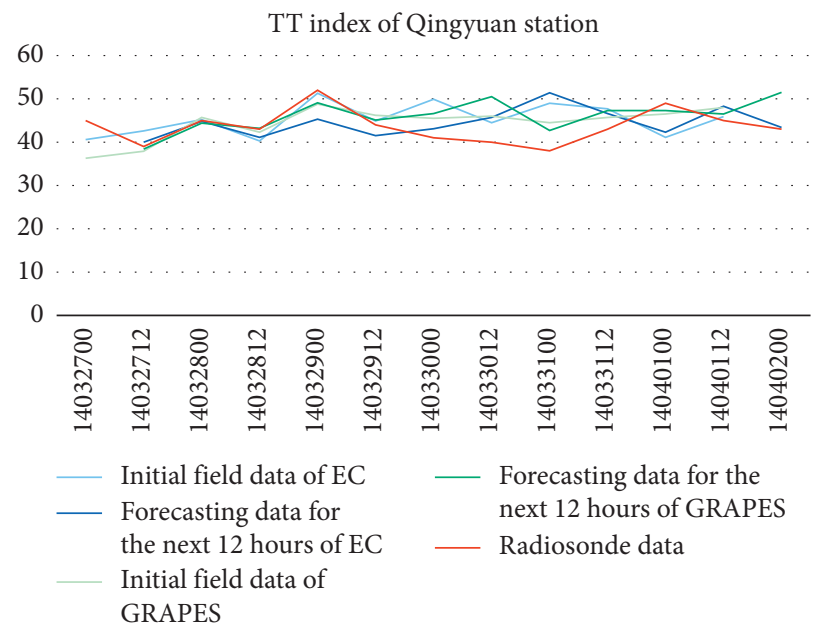

(d)

FIGURE 1: TT indexes calculated based on the two NWP models and soundings of 4 stations. 


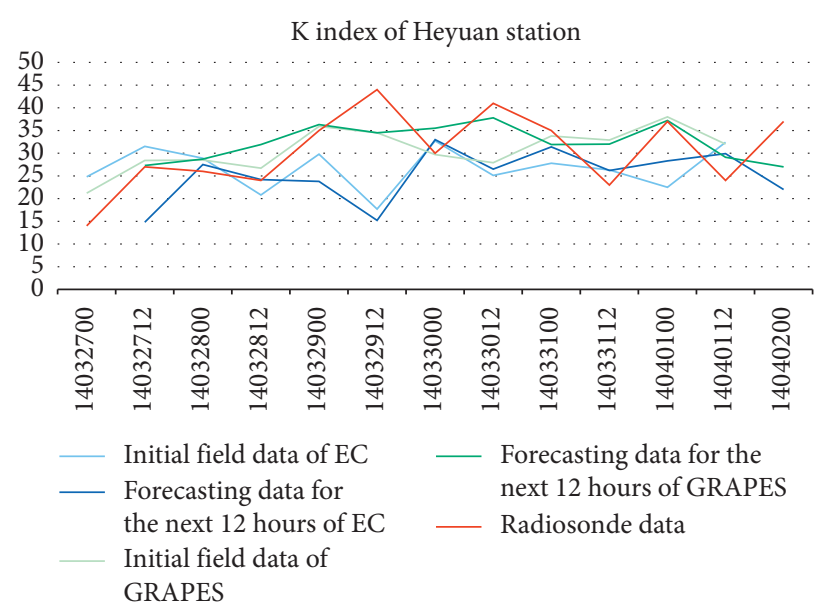

(a)

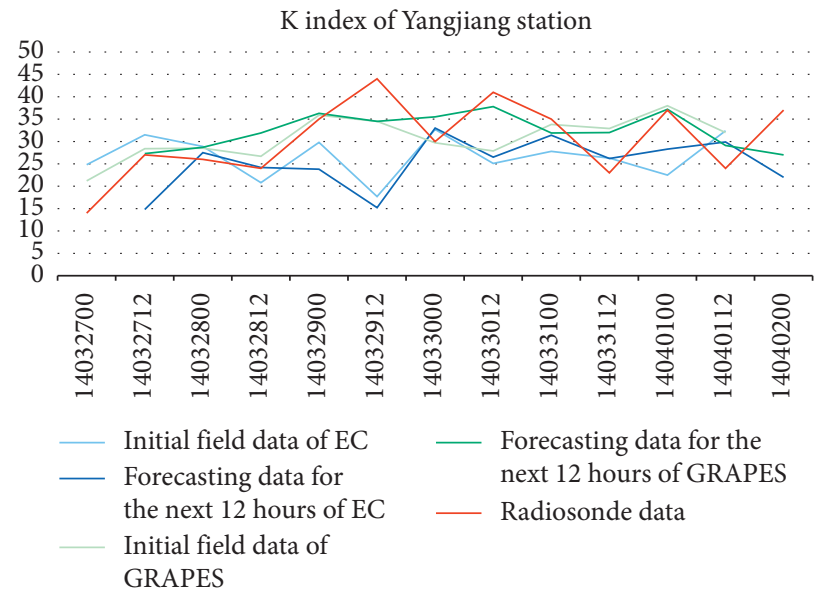

(c)

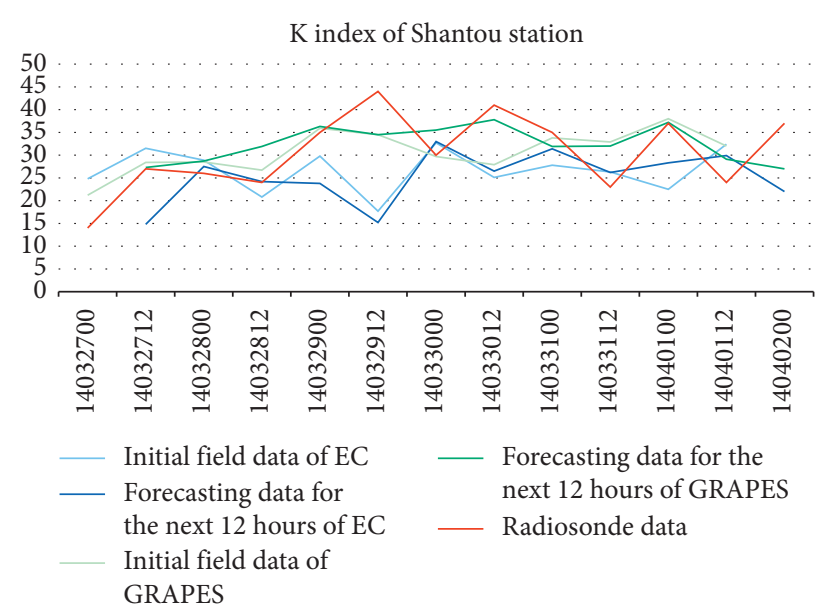

(b)

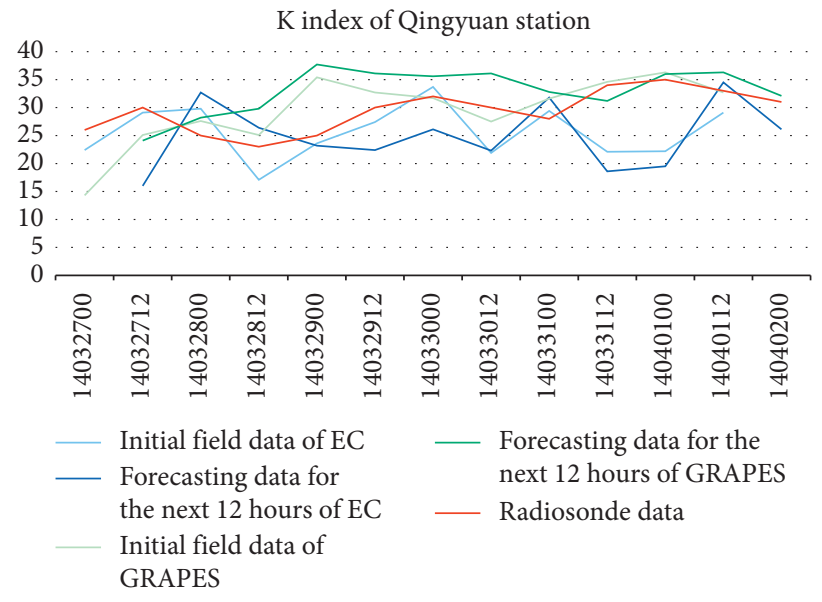

(d)

Figure 2: $K$ indexes calculated based on the two NWP models and soundings of 4 stations.

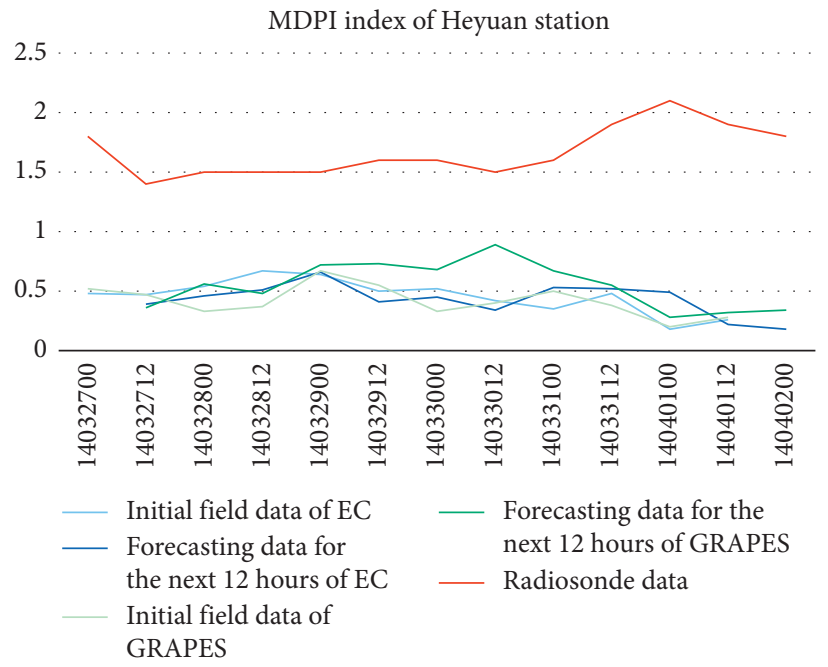

(a)

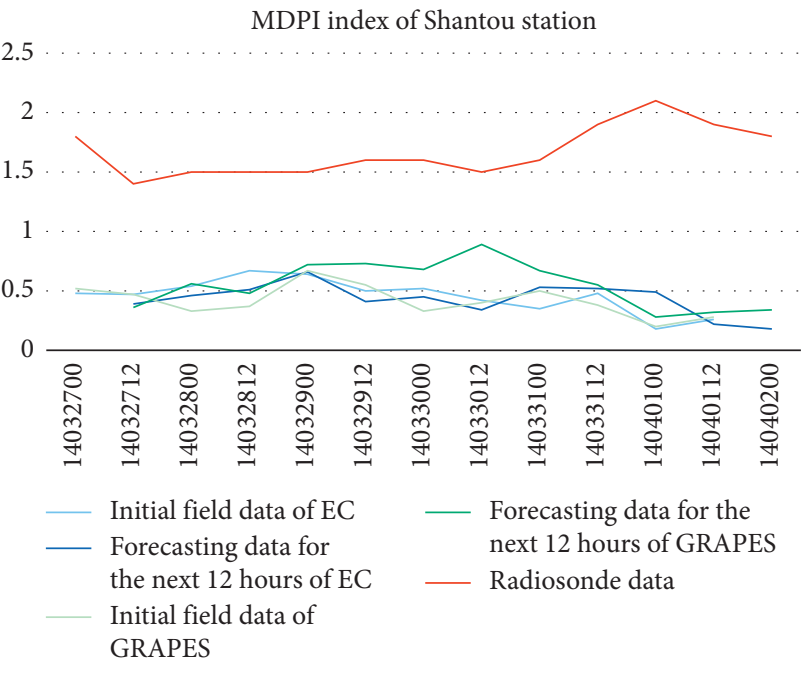

(b)

FIgURE 3: Continued. 


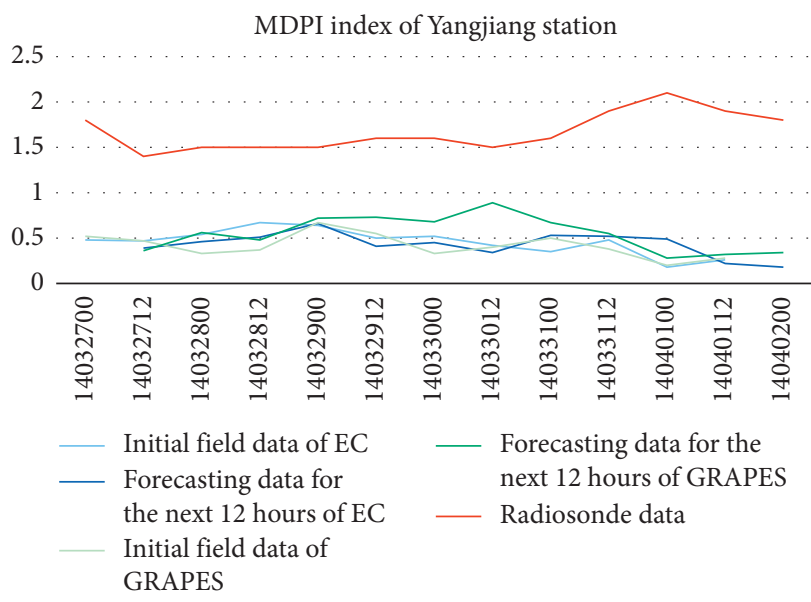

(c)

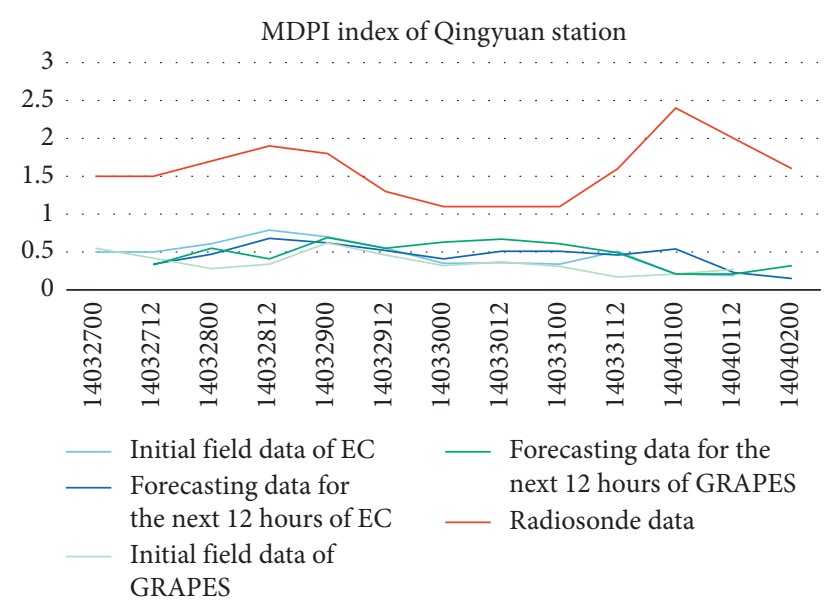

(d)

FIgURE 3: MDPI indexes calculated by two models data and radiosonde data of the 4 stations.

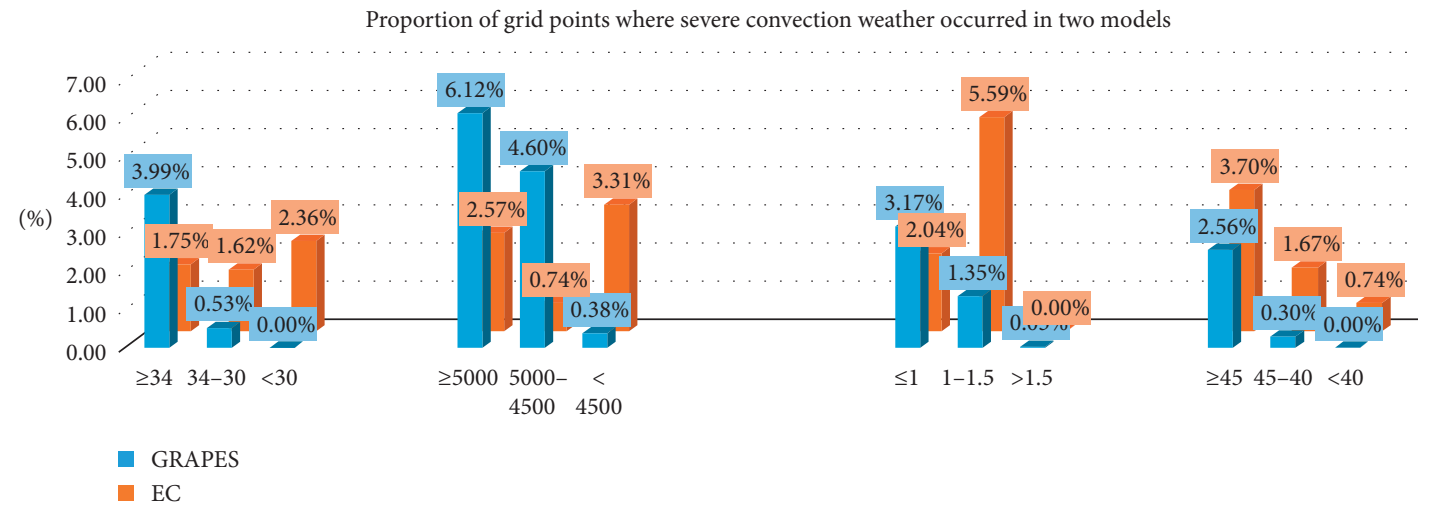

Figure 4: Proportion of grid points where severe convection weather occurred on two models.

$$
\begin{aligned}
\mathrm{POD} & =\frac{X}{X+Y}, \\
\mathrm{FAR} & =\frac{Z}{X+Z}, \\
\mathrm{CSI} & =\frac{X}{X+Y+Z} .
\end{aligned}
$$

where $X$ is the number of successful forecasting zones, $Y$ is the number of missed forecasting zones, and $Z$ is the number of false alarm zones.

After the goodness-of-fit test of the model itself, the realtime forecasts by the two forecast equations were evaluated in the first flooding season of 2015 (Table 8).

As threshold of $P$ in GRAPES went from 0.03 to 0.1 , POD had been falling from $62.64 \%$ to $10.84 \%$, and CSI first rose from $5.86 \%$ to $6.49 \%$ and then declined to $5.11 \%$, while FAR stayed above $91 \%$. As threshold of $P$ in EC rose from 0.02 to 0.1 , POD has been falling from $72.45 \%$ to $1.88 \%$, and CSI first rose from $4.00 \%$ to $5.98 \%$ and then declined to $1.26 \%$, while FAR stayed above $92 \%$.

\section{Contrast Analysis of Indexes on NWPs and Soundings}

Comparing the indexes calculated using the NWP models grid data nearest to the radiosonde station and the indexes calculated using soundings of the station, it was found that the errors of TT index were small between the soundings' and the two NWP models', including their initial's and the forecasting's in the next 12 hours (Figure 1).

The errors of $K$ index between the GRAPES ${ }^{\prime}$, including the initial's and the forecasting's in the next 12 hours, and the soundings' were smaller than the EC's. Meanwhile, the $K$ indexes of the two NWPs were relatively discrete compared to the soundings', and the errors of the 4 stations were all greater than TT indexes' (Figure 2).

The NWP MDPI indexes of the 4 stations were greater than the soundings' by 1 to 1.5 , their trends of change were consistent with the soundings' (Figure 3).

Through the spatial distribution analysis, it was found that severe convection weather occurred at $4 \%$ of the grids where GRAPES $K$ indexes were greater than 34 , 


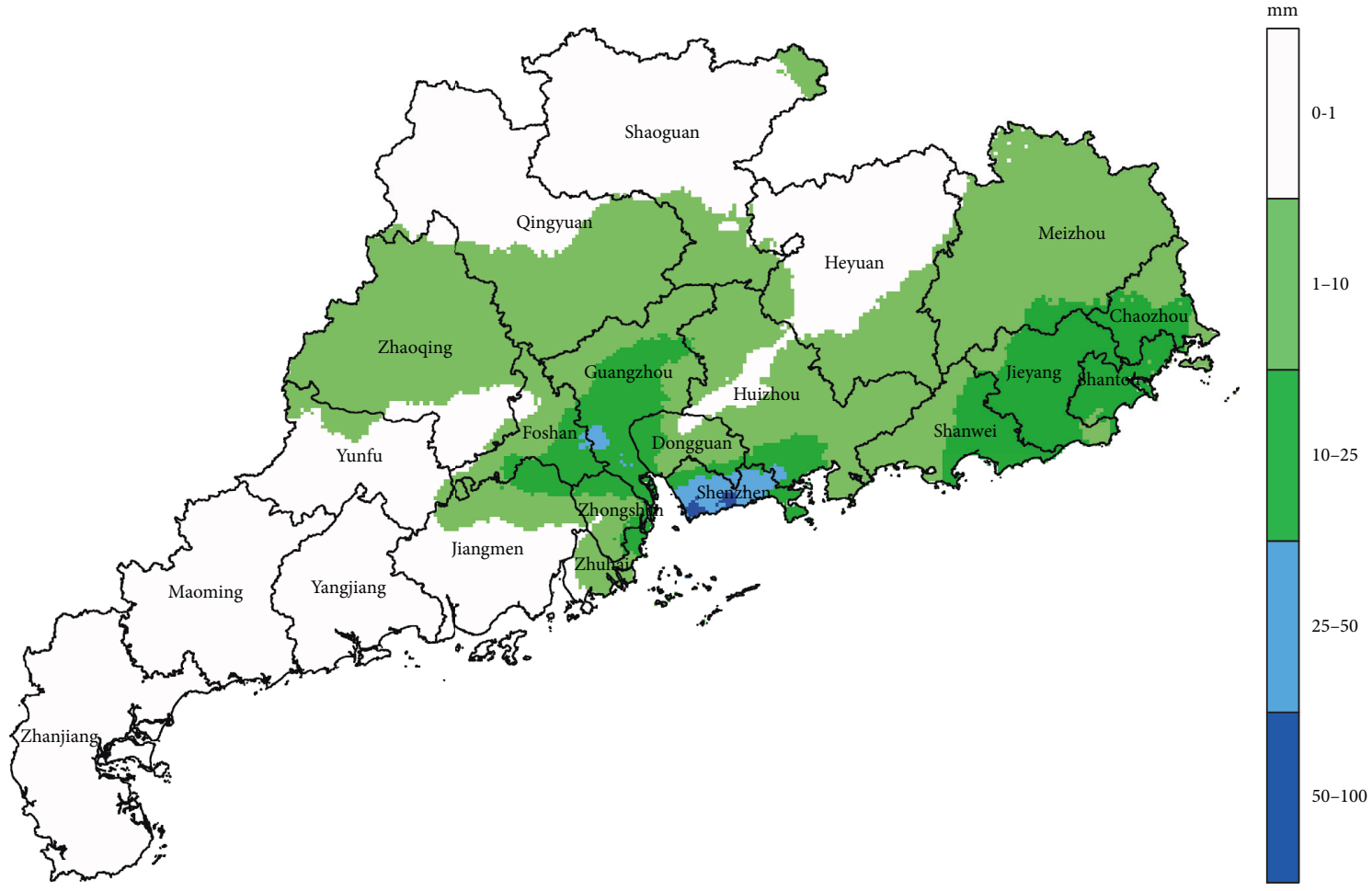

FIgure 5: 1-hour cumulative precipitation chart of Guangdong Province at 12:00 (UTC, the same as follows) on March $30,2014$.

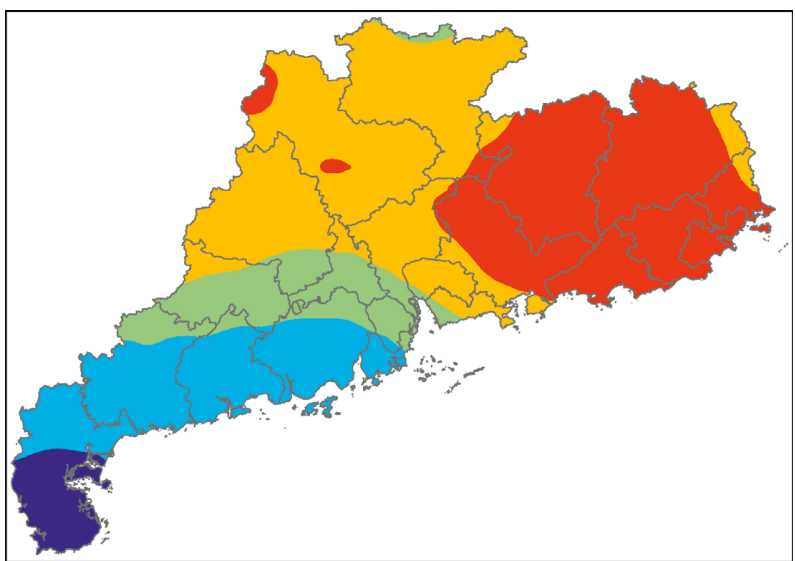

$\mathrm{K}$ index

19.60119247 to 25.48326829

25.4832683 to 30.03207359

30.0320736 to 33.79660211

33.79660212 to 36.77685385

36.77685386 to 39.60025024

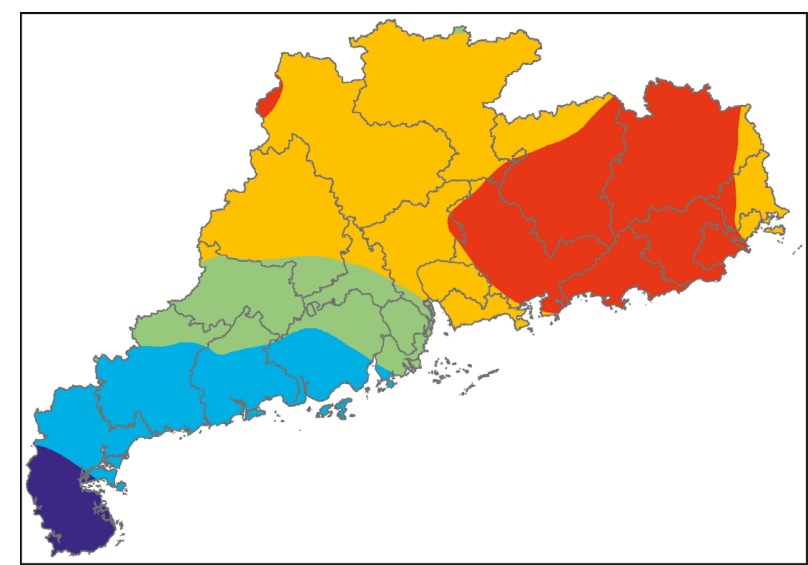

IQ index

3,561 .

,561.280518 to $3,894.423535 \square 4,560.709571$ to $4,893.852588$

, 894.423536 to $4,227.566553$

$4,893.852589$ to $5,226.995605$

$4,227.566554$ to $4,560.70957$

(b)

Figure 6: Continued. 


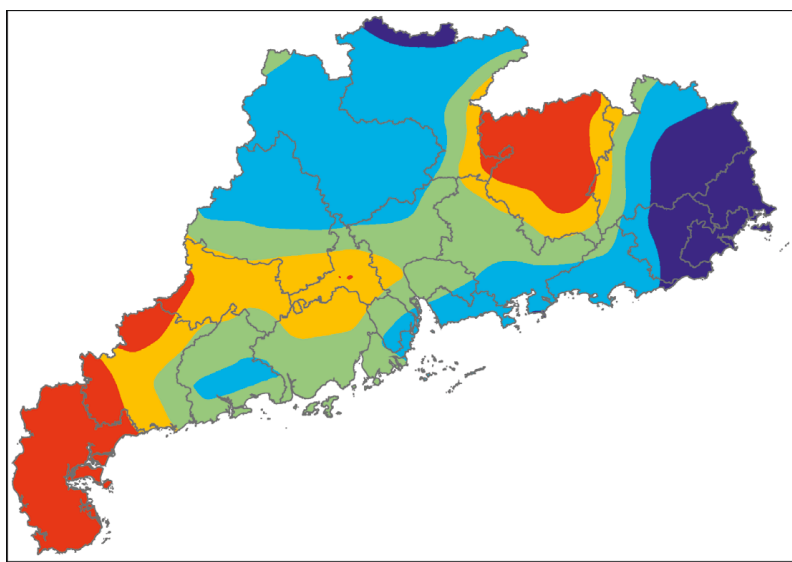

MDPI index

0.056040246 to 0.213658989

0.213658989 to 0.357054721

0.357054721 to 0.469021252
0.469021252 to 0.578041295

0.578041295 to 1.0755409

(c)

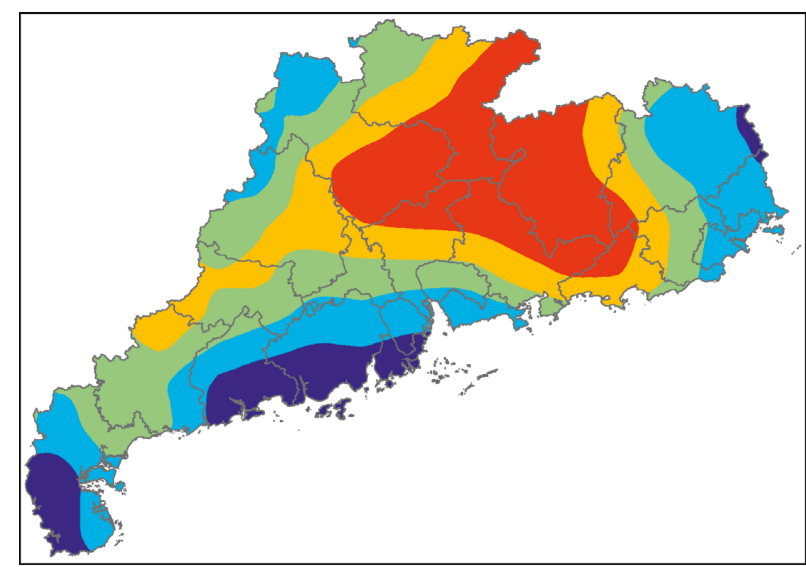

TT index

44.93721771 to $47.13298932 \square 48.86649324$ to 49.79102864
47.13298933 to 48.05752474
48.05752475 to 48.86649323 49.79102865 to 50.83113098

(d)

Figure 6: $K$ index (a), IQ index (b), MDPI index (c), and TT index (d) calculated by initial field data of GRAPES at 12:00 on March 30, 2014.

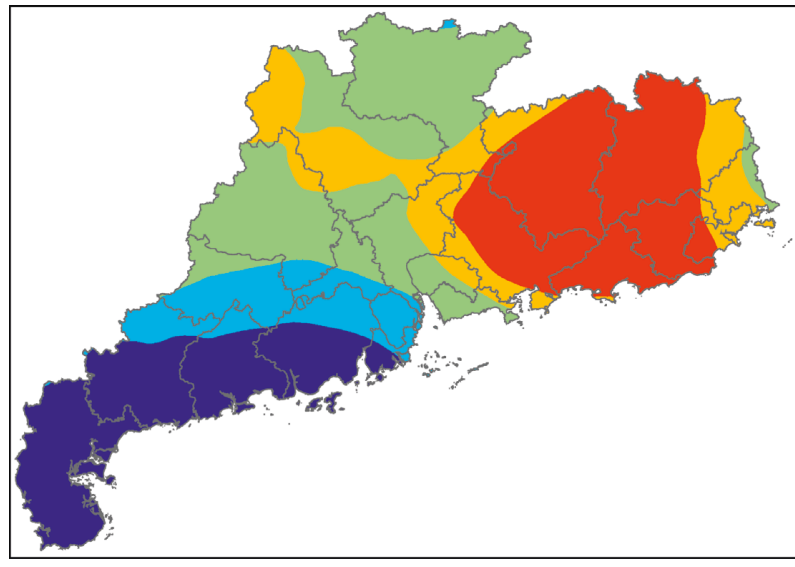

$P$ index

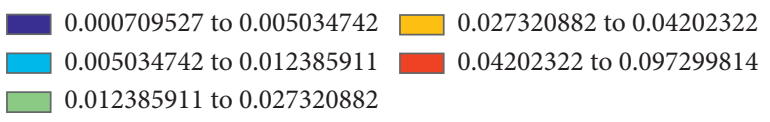

Figure 7: $P$ index calculated by initial field data of GRAPES at 12:00 on March 30, 2014.

meanwhile at $1.75 \%$ for EC $K$ index. In the same time, severe convection weather occurred in the grid at $10.72 \%$ and $3.31 \%$ where IQ index was greater than 4500 , at $4.52 \%$ and $7.63 \%$ where MDPI index was less than 1.5 , and at $2.86 \%$ and $5.37 \%$ where TT index was greater than 40 , on GRAPES and EC, respectively (Figure 4).

In terms of overall forecasting evaluation, both models had their advantages, and the rates of missed forecasting were low; however, the rates of false alarm were high.

Figure 5 is the 1-hour accumulated precipitation Chart of Guangdong Province at 12:00 on March 30, 2014.

\section{Analysis of Severe Convective Weather Events}

9.1. Analysis of Initial Field Data and Actual Precipitation. Figure 5 shows the 1-hour cumulative precipitation of Guangdong Province recorded at 12:00 (UTC) on March 30, 2014.

Figure 6 shows $K$ index, IQ index, MDPI index, and TT index calculated by initial field data of GRAPES, and Figure 7 shows the $P$ index calculated by the 4 indexes.

There was a rather well corresponding relationship between $K$ index and the precipitation areas. Except for 


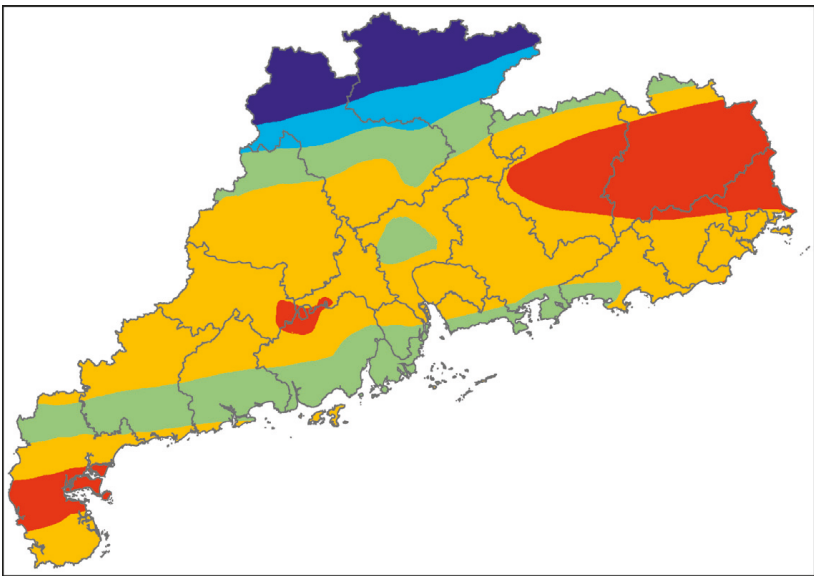

$\mathrm{K}$ index

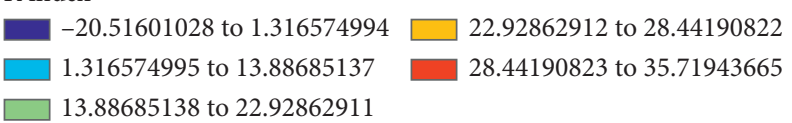

(a)

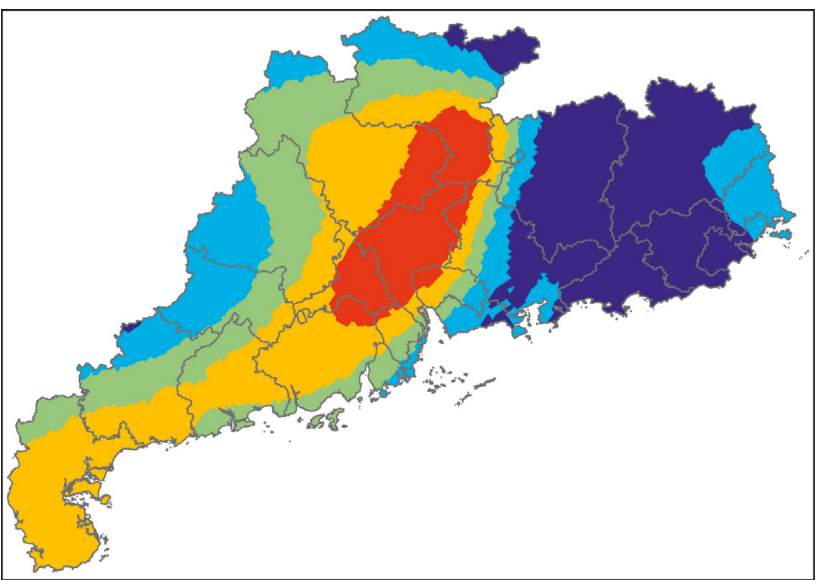

MDPI index

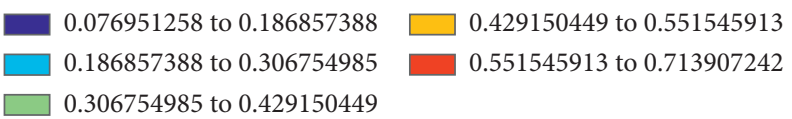

(c)

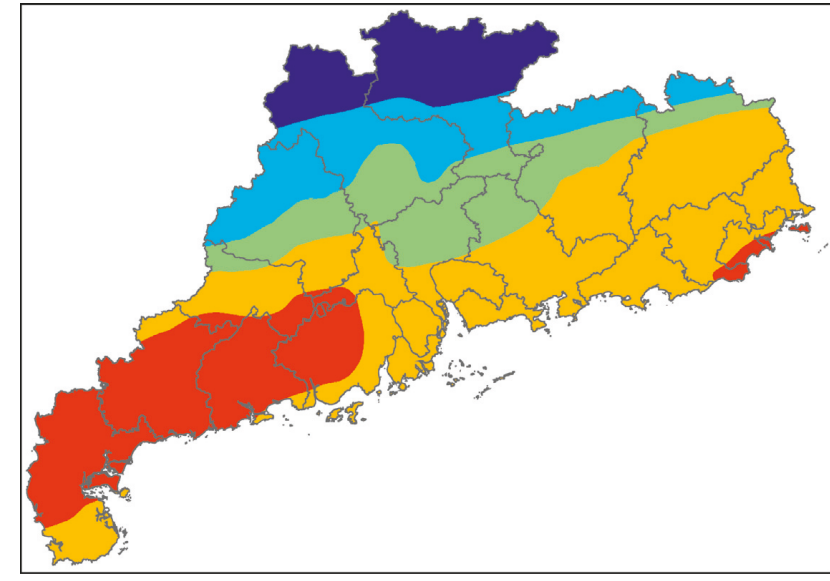

IQ index

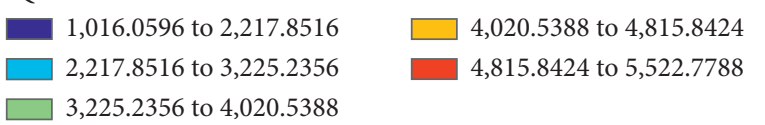

(b)

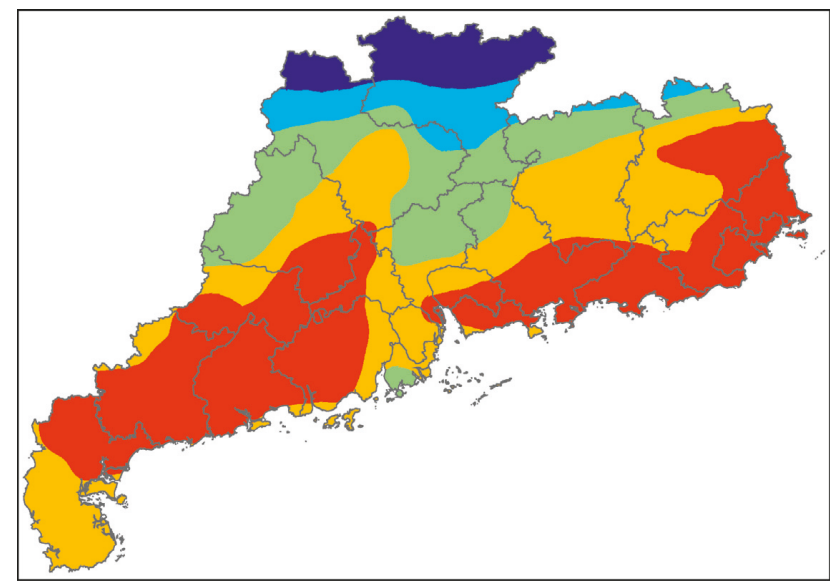

TT index

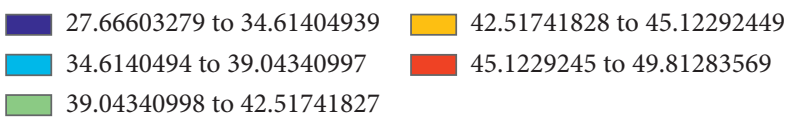

(d)

Figure 8: $K$ index (a), IQ index (b), MDPI index (c), and TT index (d) calculated by initial field data of EC at 12:00 on March 30, 2014.

the southwest of Guangdong Province, the IQ index of the whole province was of high values, indicating that the water vapor in the air over Guangdong Province was relatively high. Except for the poor correspondence between MDPI index and precipitation areas in the north of Guangdong Province, the correspondence between the two in other areas was good. TT index corresponded well with precipitation areas. $P$ index had a better fitting effect for the nonsignificant precipitation in the southwest of Guangdong Province but a worse fitting effect for the no precipitation in the north. However, generally speaking, $P$ index could well fit the precipitation in the whole region.
Figure 8 shows $K$ index, IQ index, MDPI index, and TT index calculated by initial field data of EC, and Figure 9 is the $P$ index calculated by the 4 indexes.

The high value areas of $K$ index were mainly located in the eastern part of Guangdong Province and slightly east to the precipitation areas; the high value areas of IQ index were found in the western part of Guangdong Province and west to the precipitation areas. MDPI index was a good indication for the precipitation areas in the eastern part but failed to reflect the precipitation in the central part. The high value areas of TT index were to the west of the precipitation areas. To sum up, the high value areas of $P$ index were to the south and west of the precipitation areas, and false alarm of precipitation was 


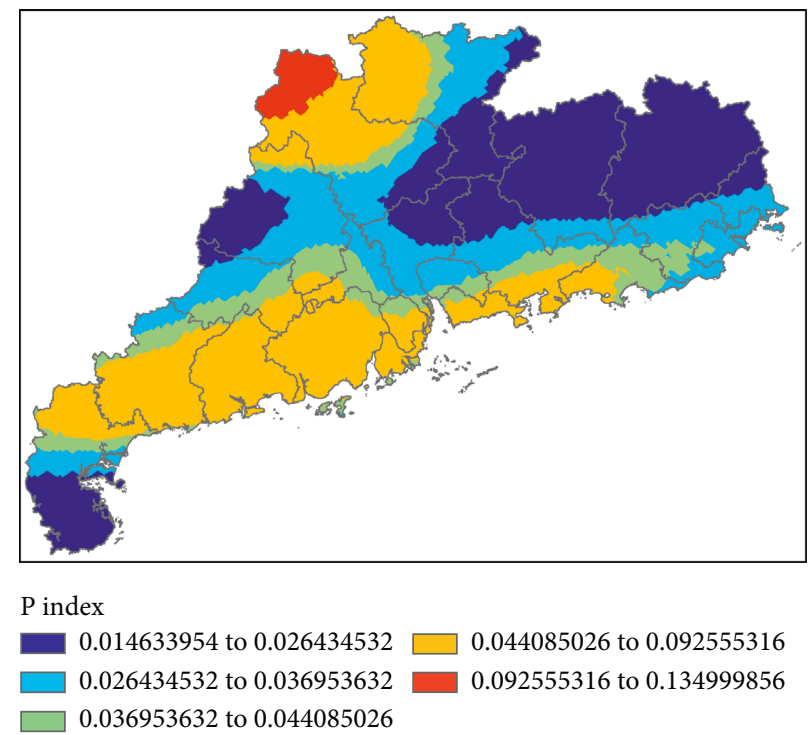

Figure 9: $P$ index calculated by initial field data of EC at 12:00 on March 30, 2014.

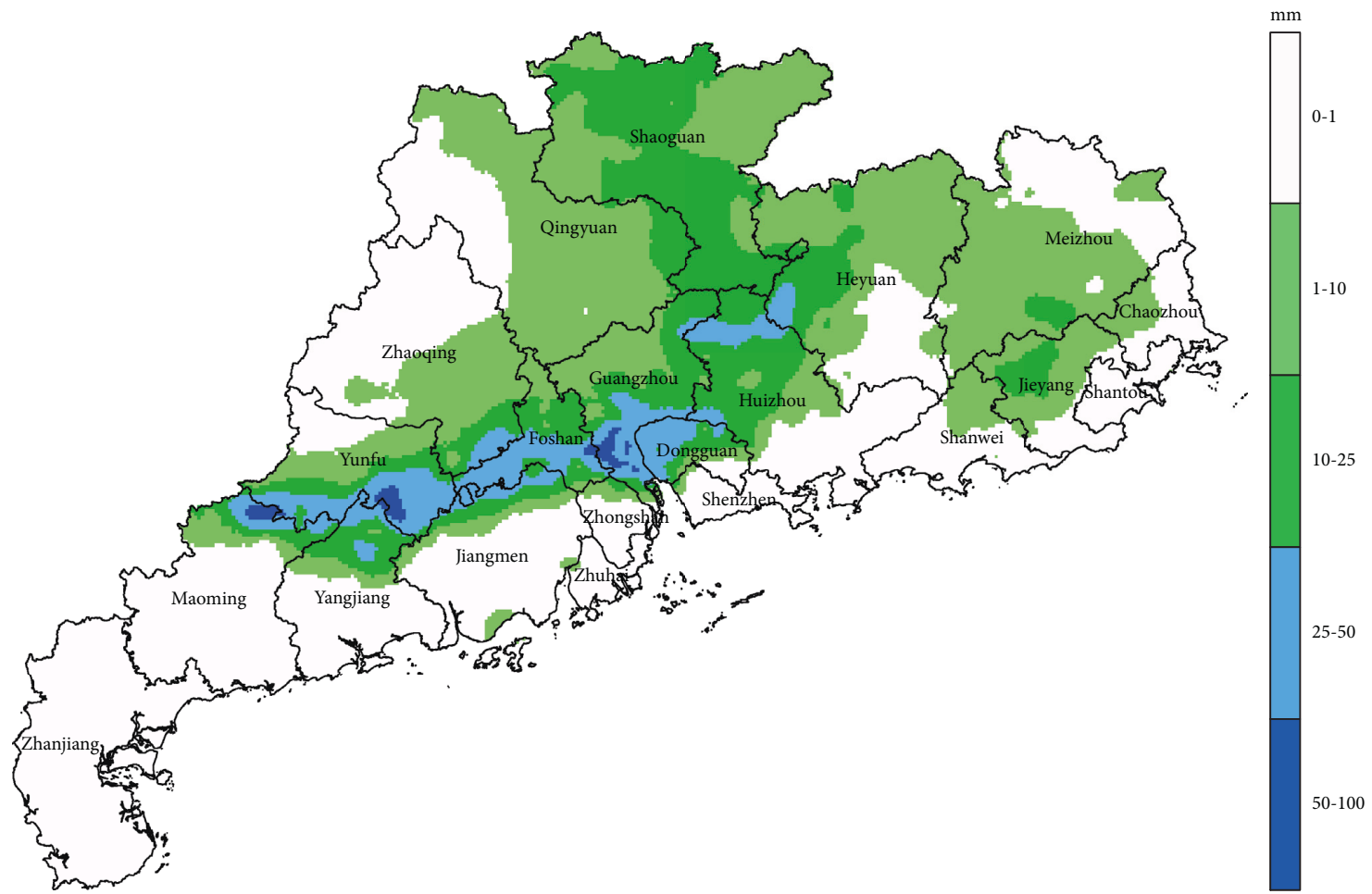

FIGURE 10: 1-hour cumulative precipitation chart of Guangdong province at 00:00 on March 31, 2014.

made for the northern part. In this event, the forecast effect of GRAPES was better than that of EC.

9.2. Analysis of Forecasting Data and Actual Precipitation. Figure 10 shows the 1-hour cumulative precipitation of Guangdong Province recorded at 00:00 on March 31, 2014.

Figure 11 shows $K$ index, IQ index, MDPI index, and TT index calculated by forecasting data for the next 12 hours (i.e., 00:00 on March 31, 2014) of GRAPES, and Figure 12 shows the $P$ index calculated by the 4 indexes.

All 4 indexes indicated that there would be short-term heavy precipitation in the central and eastern parts of Guangdong Province. $\mathrm{P}$ index also predicted that there would be short-term heavy precipitation in most parts of Guangdong Province except for the southwest regions. As shown by the actual weather, $P$ index accurately reflected the event that there was no short-term heavy precipitation in the 


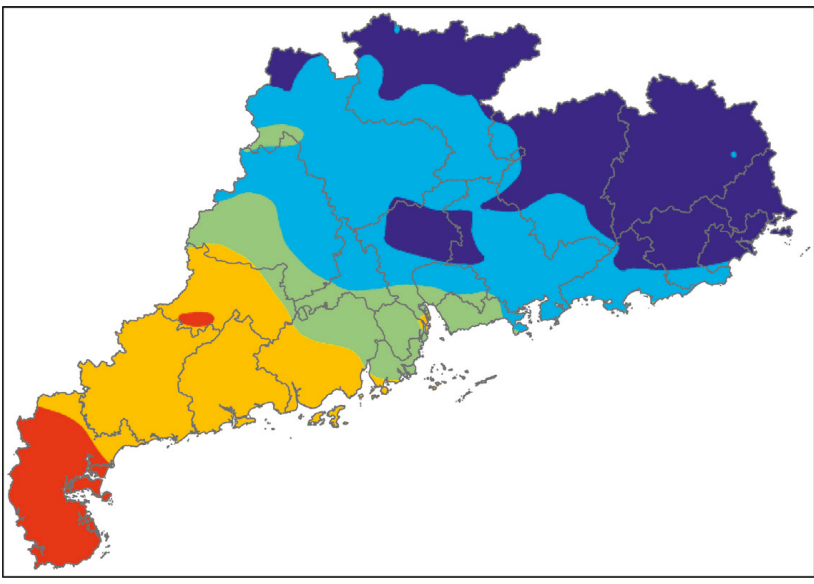

MDPI index

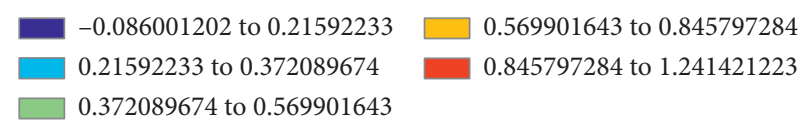

(a)

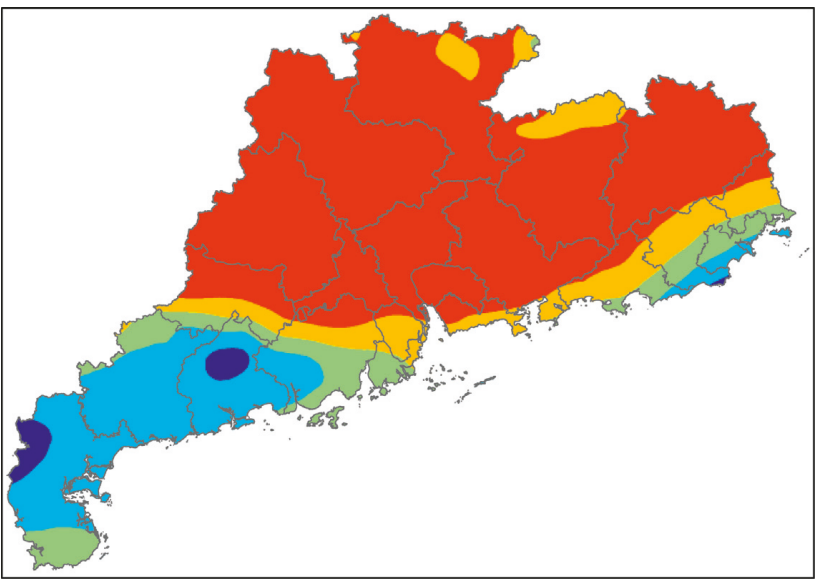

$\mathrm{K}$ index

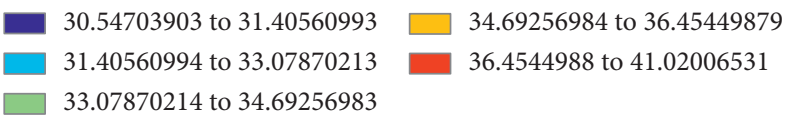

(c)

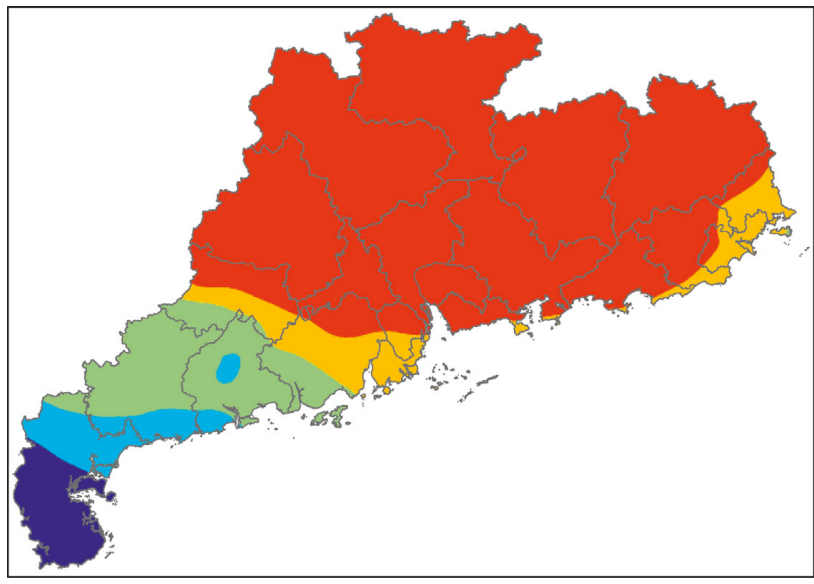

IQ index

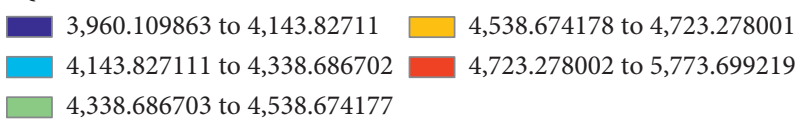

(b)

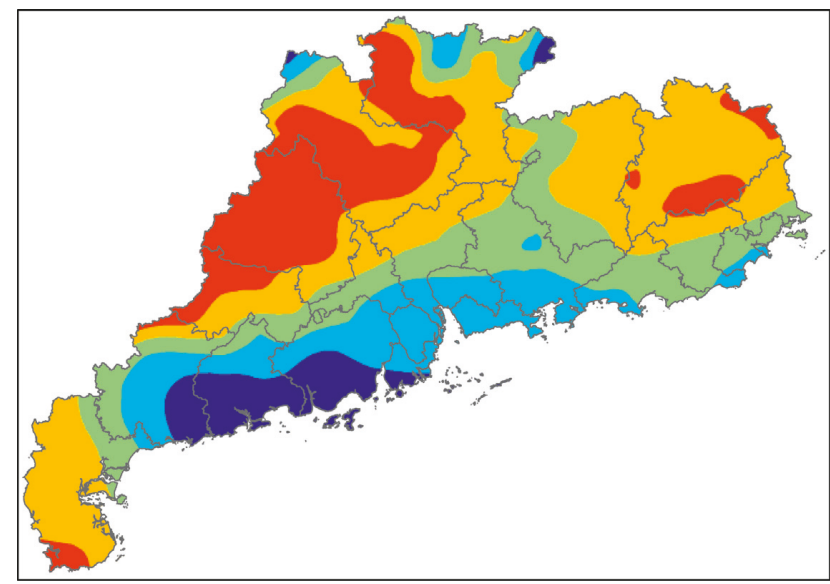

TT index

\begin{tabular}{|l|l}
41.70584869 to 43.98715946 & $\square 6.79746983$ to 47.95465644 \\
43.98715947 to 45.54109578 & $\square$ \\
\hline & $\square .95465645$ to 50.13677979 \\
\hline & $\square 5.54109579$ to 46.79746982
\end{tabular}

(d)

Figure 11: $K$ index (a), IQ index (b), MDPI index (c), and TT index (d) calculated by forecasting data for the next 12 Hours (i.e., 00:00 on March 31, 2014) of GRAPES.

southwest region, but false alarm of precipitation was made for the central and eastern parts.

Figure 13 shows $K$ index, IQ index, MDPI index, and TT index calculated by forecasting data for the next 12 hours (i.e., 00:00 on March 31, 2014) of EC, and Figure 14 shows the $P$ index calculated by the 4 indexes.

The corresponding relation between the high value areas of $K$ index and the precipitation areas was poor, located in the eastern and western parts, respectively. The high value areas of IQ index were to the south of the precipitation areas. The high value areas of MDPI index were to the east and north of the precipitation areas. The distribution of the high value areas of TT index was similar to that of IQ index. The forecast effects of the 4 indexes were all unsatisfactory, but the high value areas of $\mathrm{P}$ index perfectly matched the precipitation areas in this event. In this event, the forecast effect of EC was obviously better than that of GRAPES. Although the precipitation areas were also forecasted by GRAPES, its false alarm rate was higher.

In general, according to one effect test of initial field and one effect test of forecast field, GRAPES did not generate missed alarm, while it may make false alarm. Compared with the actual precipitation areas, the precipitation areas calculated by EC model may have a deviation in location, resulting in both false alarm and missed alarm in the model test, which led 

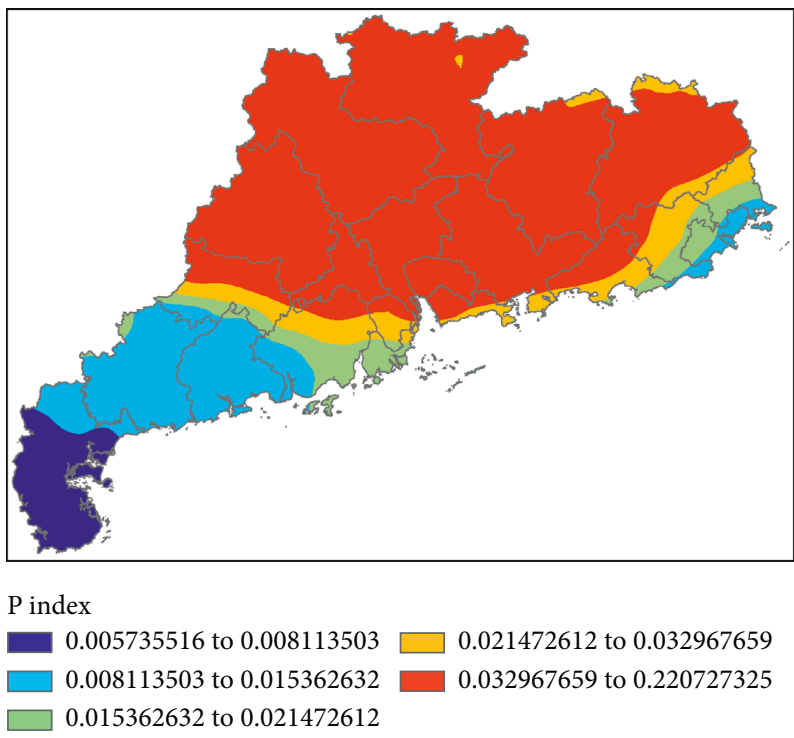

Figure 12: $P$ index calculated by forecasting data for the next 12 hours (i.e., 00:00 on March 31, 2014) of GRAPES.

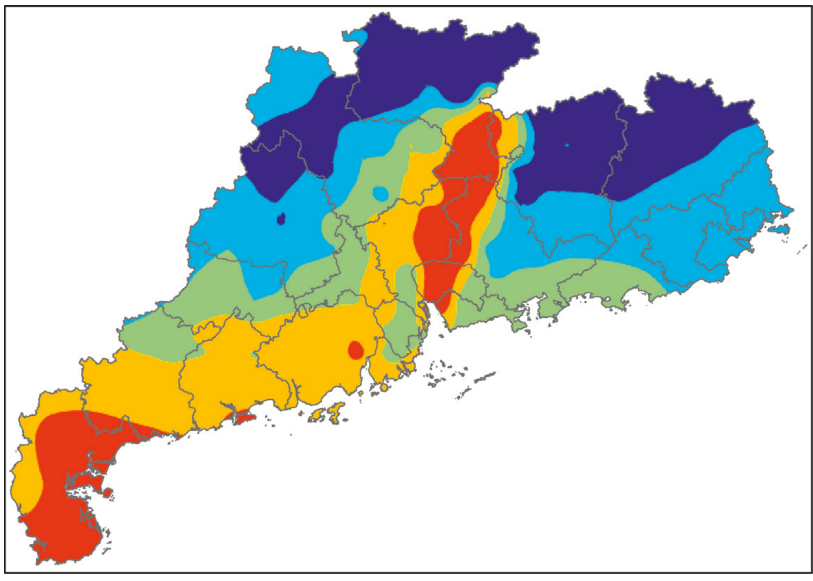

MDPI index

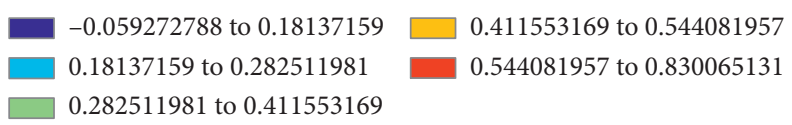

(a)

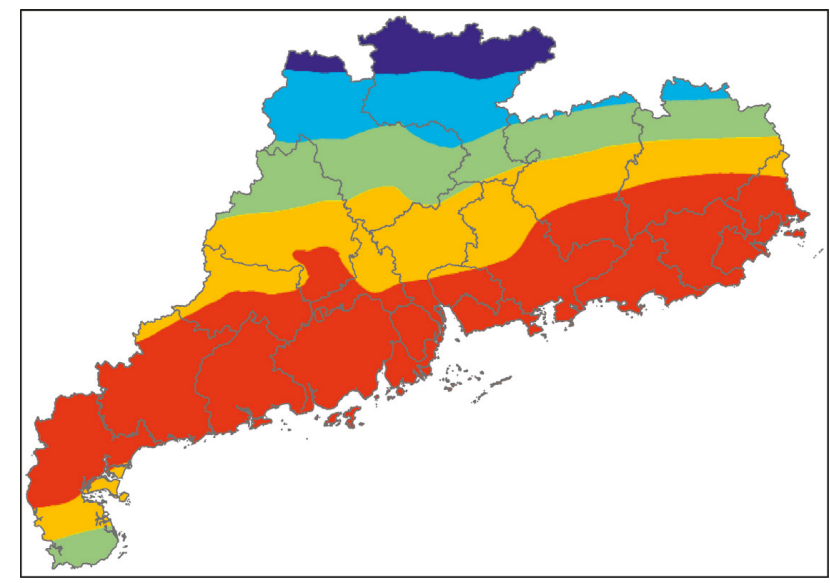

IQ index

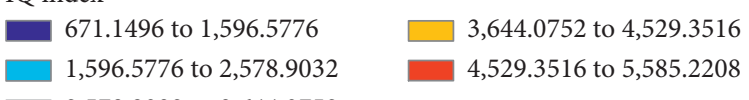

$2,578.9032$ to $3,644.0752$

(b)

FIgURE 13: Continued. 


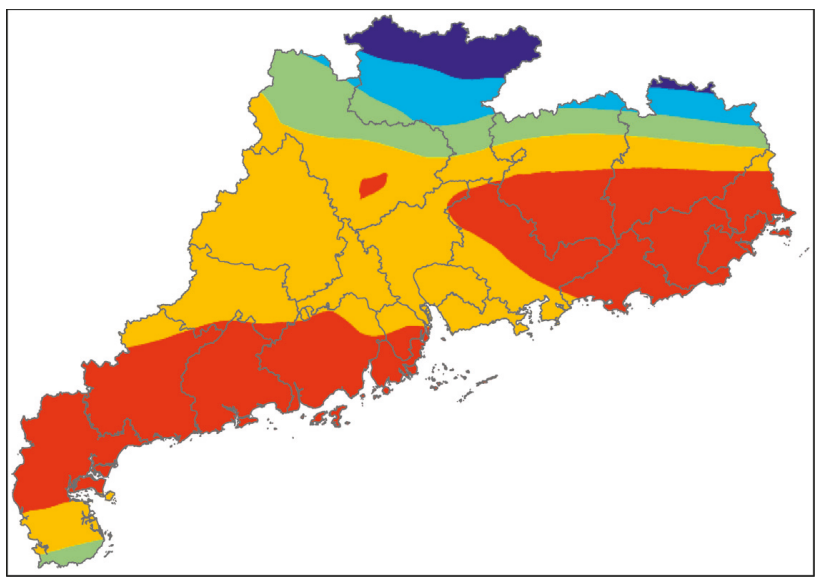

$\mathrm{K}$ index

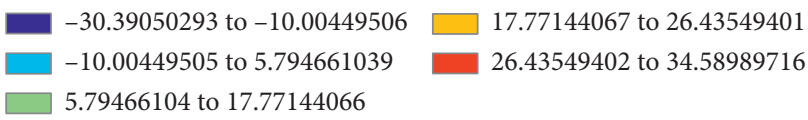

(c)
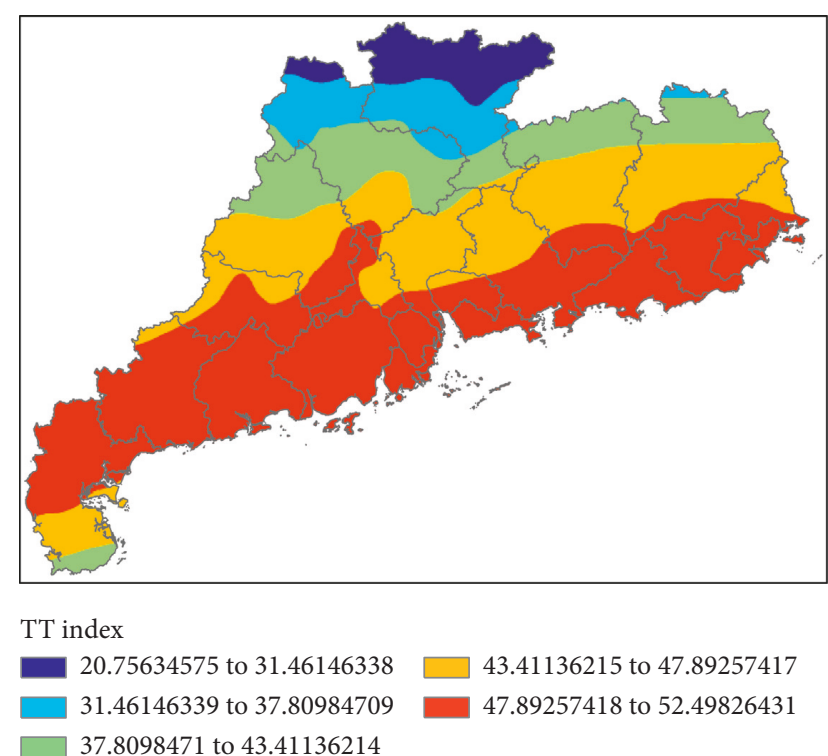

(d)

Figure 13: $K$ index (a), IQ index (b), MDPI index (c), and TT index (d) calculated by forecasting data for the next 12 hours (i.e., 00:00 on March 31, 2014) of EC.

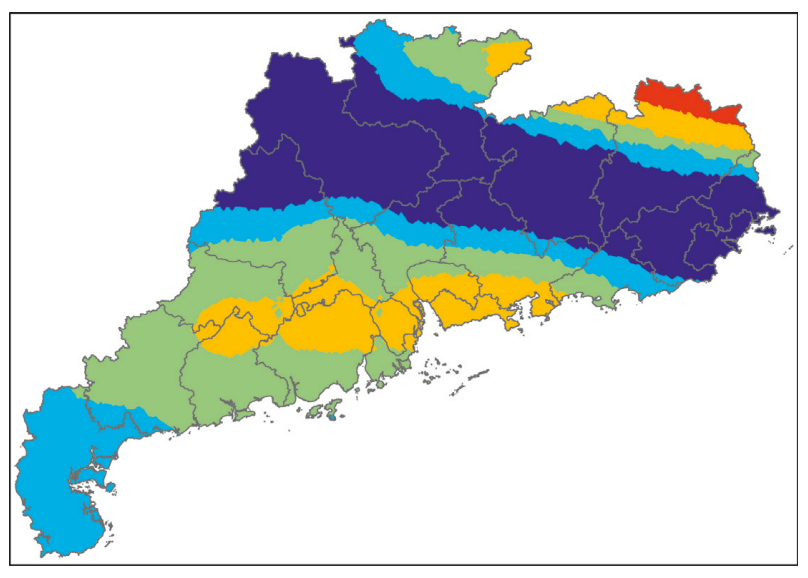

$\mathrm{P}$ index

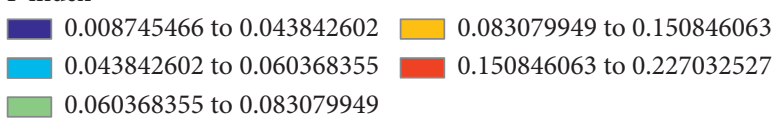

Figure 14: $P$ index calculated by forecasting data for the next 12 hours (i.e., 00:00 on March 31, 2014) of EC.

to test results of a certain event even worse than those of the situation with only false alarm.

\section{Summary and Discussion}

(1) The correlation coefficients between 16 indexes and severe convection weather were analyzed. The correlation coefficients between $K$ index, TT index, MDPI index, IQ index, and severe convection weather were better than the other indexes. Then, the 4 indexes were selected for binary logistic regression analysis.
(2) Comparing the indexes calculated using the NWP models grid data nearest to the radiosonde station and the indexes calculated using soundings of the station, it was found that the errors of TT index were small between the soundings' and the two NWP models', including their initial's and the forecasting's in the next 12 hours. The errors of $K$ index between the GRAPES', including the initial's and the forecasting's in the next 12 hours, and the soundings' were smaller than the EC's. Meanwhile, the $K$ indexes of the two NWPs were relatively discrete compared to the soundings', and the errors of the 4 stations were all greater than TT indexes'. The NWP MDPI indexes of the 4 stations were greater than the soundings' by 1 to 1.5 , and their trends of change were consistent with those of the soundings'.

(3) Through the spatial distribution analysis, it was found that, in terms of overall forecasting evaluation, both models had their advantages, and the rates of missed forecasting were low; however, the rates of false alarm were high.

(4) According to one effect test of initial field and one effect test of forecast field, GRAPES did not generate missed alarm, while it may make false alarm. Compared with the actual precipitation areas, the precipitation areas calculated by the EC model may have a deviation in location, resulting in both false alarm and missed alarm in the model test, which led to test results of a certain event even worse than those of the situation with only false alarm.

(5) Binary logic regression is an algorithm of machine learning, and it can improve the accuracy of the 
model in the future by further applying machine learning to NWP.

(6) With the development of NWP, the accuracy of the model will be further improved. And, the accuracy of severe convection weather forecasting will be further improved by applying products of the models.

\section{Data Availability}

The data used to support the findings of this study are available from the corresponding author upon request.

\section{Conflicts of Interest}

The authors declare that they have no conflicts of interest.

\section{Acknowledgments}

This paper was supported by the Natural Science Foundation of Guangdong Province of China-Major Basic Research and Cultivation Projects (grant no. 2015A030308014) and the Special Fund for Promoting High-quality Economic Development of Guangdong Province of Ocean Economic Development Project (grant no. GDOE[2019]A11).

\section{References}

[1] Y. Li and L. Jianwen, "On the progress of application for dynamic and energetic convective parameters associated with severe convective weather forecasting," Acta Meteorologica Sinica, vol. 62, no. 8, pp. 401-409, 2004.

[2] D. Kleinbaum, Logistic Regression, Springer-Verlag, New York, NY, USA, 1994.

[3] J. L. Sánchez, J. L. Marcos, M. T. de la Fuente, and A. Castro, "A logistic regression model applied to short term forecast of hail risk," Physics and Chemistry of the Earth, vol. 23, no. 5-6, pp. 645-648, 1998.

[4] E. Gascón, A. Merino, J. L. Sánchez et al., "Spatial distribution of thermodynamic conditions of severe storms in Southwestern Europe," Atmospheric Research, vol. 164-165, pp. 194-209, 2015.

[5] F. Trenton and C. F. Labosier, "Spatial patterns of drought persistence in the Southeastern United States," International Journal of Climatology, vol. 34, no. 7, pp. 2229-2240, 2014.

[6] C. C. Lee, "Utilizing synoptic climatological methods to assess the impacts of climate change on future tornado-favorable environments," Natural Hazards, vol. 62, no. 2, pp. 325-343, 2012.

[7] S. Dasgupta and U. K. De, "Binary logistic regression models for short term prediction of premonsoon convective developments over Kolkata (India)," International Journal of Climatology, vol. 27, no. 6, pp. 831-836, 2007.

[8] J. Holden and A. Wright, "UK tornado climatology and the development of simple prediction tools," Quarterly Journal of the Royal Meteorological Society, vol. 130, no. 598, pp. 10091021, 2004.

[9] M. Pablo, A. Merino, J. L. Sánchez, L. López, and E. GarcíaOrtega, "Spatial patterns of thermodynamic conditions of hailstorms in Southwestern France," Atmospheric Research, vol. 189, pp. 111-126, 2017.

[10] G. Pang, "Comparative analyzing of the indeces in the first and second flooding season of the pearl river delta and choosing of the thresholds," Journal of Tropical Meteorology, vol. 28, pp. 919-923, 2012.

[11] G. Pang, "Study on a severe convective weather potential forecasting method in the first flooding season of the pearl river delta," Journal of Tropical Meteorology, vol. 28, pp. 564-568, 2012.

[12] G. Pang, "Study on a zoning severe convective weather potential forecasting method in the first flooding season of Guangdong," Journal of Tropical Meteorology, vol. 32, pp. 265-272, 2016

[13] Z. Wu and G. Pang, "Classification pattern and physical threshold of severe concective weather during pre-flood period in Guangdong," Journal of Natural Disasters, vol. 6, no. 25, pp. 166-175, 2016. 

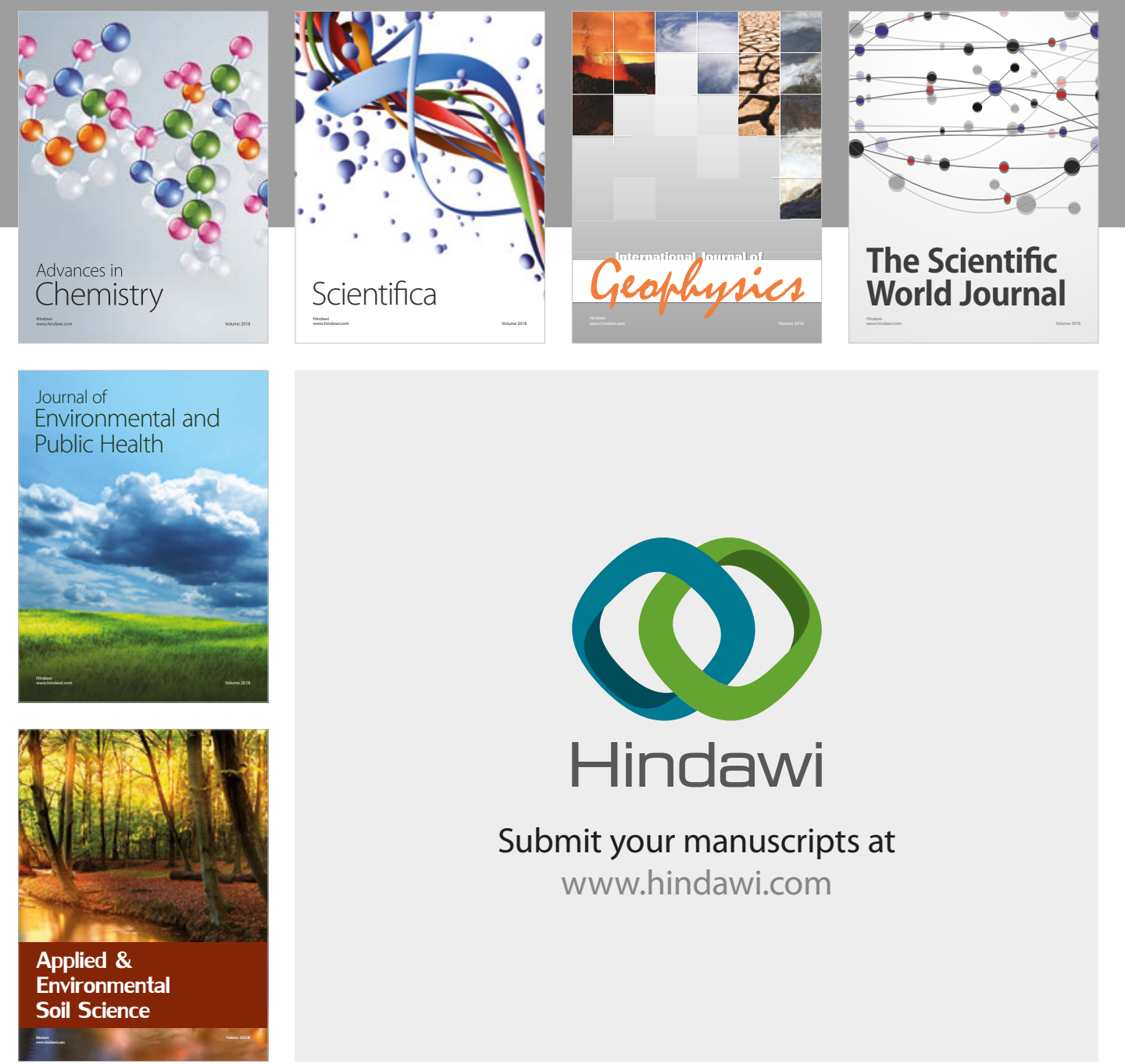

The Scientific

\section{World Journal}
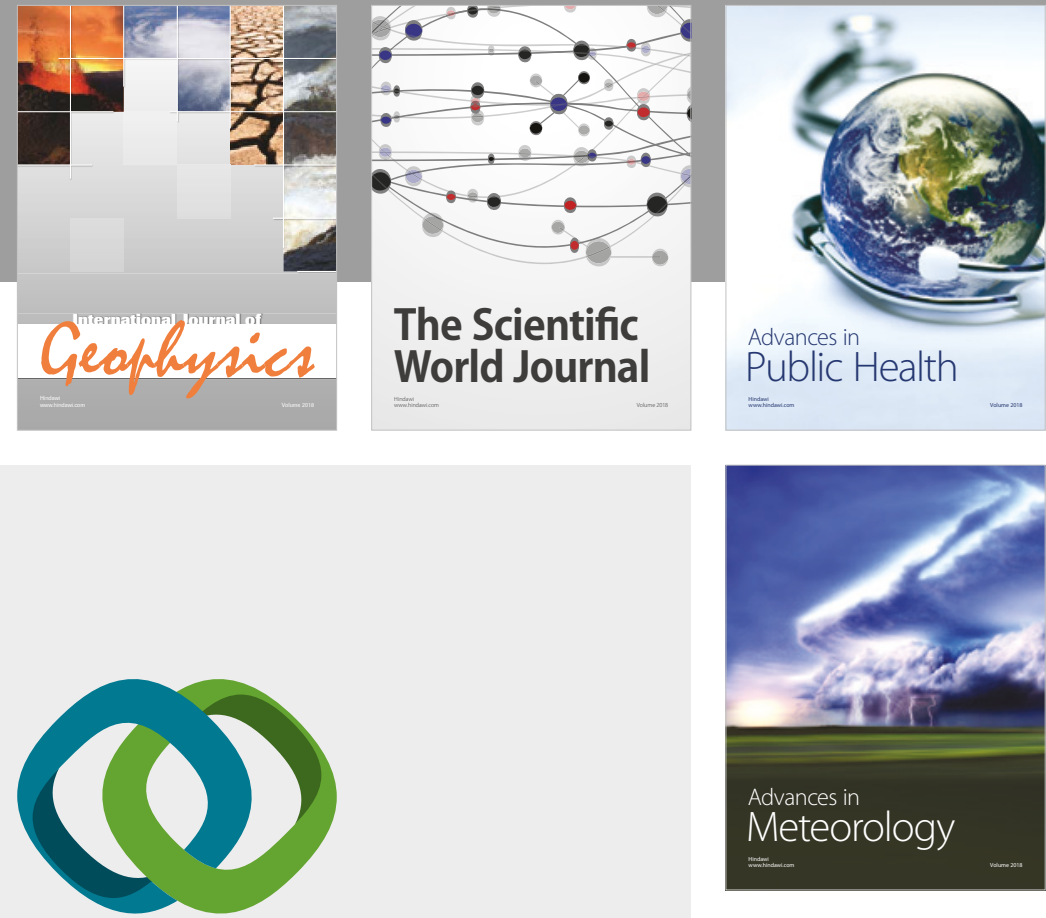

Advan

Public Health

\section{Hindawi}

Submit your manuscripts at

www.hindawi.com
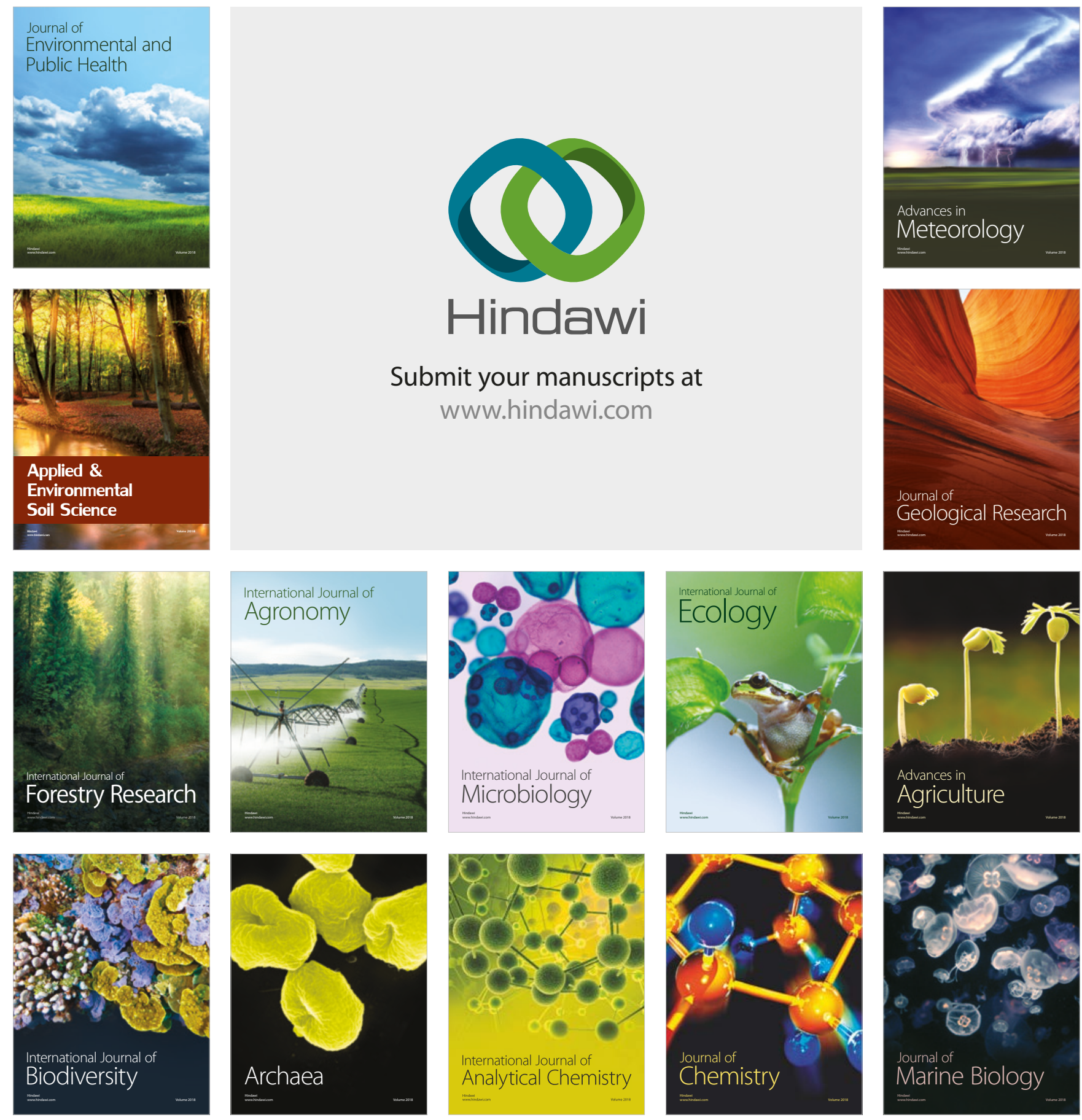